\title{
Phosphodiesterase-4D Knock-Out and RNA Interference-Mediated Knock-Down Enhance Memory and Increase Hippocampal Neurogenesis via Increased cAMP Signaling
}

\author{
Yun-Feng Li, ${ }^{1,2}$ Yu-Fang Cheng, ${ }^{1,2}$ Ying Huang, ${ }^{1,3}$ Marco Conti, ${ }^{4}$ Steven P. Wilson, ${ }^{5}$ James M. O’Donnell, ${ }^{1,3}$ \\ and Han-Ting Zhang ${ }^{1,2}$ \\ Departments of ${ }^{1}$ Behavioral Medicine and Psychiatry, ${ }^{2}$ Physiology and Pharmacology, and ${ }^{3}$ Neurobiology and Anatomy, West Virginia University Health \\ Sciences Center, Morgantown, West Virginia 26506, ${ }^{2}$ Division of Reproductive Biology, Department of Obstetrics and Gynecology, University of California, \\ San Francisco, California 94143, and 5Department of Pharmacology, Physiology, and Neuroscience, University of South Carolina School of Medicine, \\ Columbia, South Carolina 29208
}

\begin{abstract}
Phosphodiesterase-4 (PDE4) plays an important role in mediating memory via the control of intracellular cAMP signaling; inhibition of PDE4 enhances memory. However, development of PDE4 inhibitors as memory enhancers has been hampered by their major side effect of emesis. PDE4 has four subtypes (PDE4A-D) consisting of 25 splice variants. Mice deficient in PDE4D displayed memory enhancement in radial arm maze, water maze, and object recognition tests. These effects were mimicked by repeated treatment with rolipram in wild-type mice. In addition, similarly as rolipram-treated wild-type mice, PDE4D-deficient mice also displayed increased hippocampal neurogenesis and phosphorylated cAMP response element-binding protein (pCREB). Furthermore, microinfusion of lentiviral vectors that contained microRNAs (miRNAs) targeting long-form PDE4D isoforms into bilateral dentate gyri of the mouse hippocampus downregulated PDE4D4 and PDE4D5, enhanced memory, and increased hippocampal neurogenesis and pCREB. Finally, while rolipram and PDE4D deficiency shortened $\alpha 2$ adrenergic receptor-mediated anesthesia, a surrogate measure of emesis, miRNA-mediated PDE4D knock-down in the hippocampus did not. The present results suggest that PDE4D, in particular long-form PDE4D, plays a critical role in the mediation of memory and hippocampal neurogenesis, which are mediated by cAMP/CREB signaling; reduced expression of PDE4D, or at least PDE4D4 and PDE4D5, in the hippocampus enhances memory but appears not to cause emesis. These novel findings will aid in the development of PDE4 subtype- or variant-selective inhibitors for treatment of disorders involving impaired cognition, including Alzheimer's disease.
\end{abstract}

\section{Introduction}

Phosphodiesterase-4 (PDE4), an enzyme that catalyzes cAMP hydrolysis, plays an important role in the mediation of memory. Inhibition of PDE4 by rolipram, a selective PDE4 inhibitor, increases cAMP and phosphorylation of CREB (Schneider, 1984; Li et al., 2009), facilitates induction of hippocampal long-term potentiation (LTP) (Barad et al., 1998), and enhances memory (Romano et al., 1996; Otmakhov et al., 2004). It also reverses memory deficits produced by pharmacological (Egawa et al., 1997; Zhang et al., 2000, 2004), physical (Imanishi et al., 1997), or

Received 0ct. 5, 2010; accepted 0ct. 24, 2010.

This work was supported by research grants from National Alliance for Research on Schizophrenia and Depression and National Institute on Aging (AG031687 to H.-T.Z.) and the National Institute of Mental Health (MH051175 and MH040697 to J.M.0.).

Correspondence should be addressed to Dr. Han-Ting Zhang, Department of Behavioral Medicine and Psychiatry, West Virginia University Health Sciences Center, Morgantown, WV 26506-9137. E-mail: hzhang@hsc.wvu.edu.

Y.-F. Li's present address: Beijing Institute of Pharmacology and Toxicology, Beijing 100850, China.

Y.-F. Cheng's present address: Department of Pharmacology, School of Pharmaceutical Sciences, Southern Medical University, Guangzhou 510515, China.

DOI:10.1523/JNEUROSCI.5236-10.2011

Copyright $\odot 2011$ the authors $\quad 0270-6474 / 11 / 310172-12 \$ 15.00 / 0$ genetic approaches (Bourtchouladze et al., 2003). Consistent with this, PDE4 is involved in hippocampal neurogenesis, which is associated with learning and memory (Bruel-Jungerman et al., 2005; Epp et al., 2007). Chronic rolipram treatment increases proliferation and survival of newborn neurons in the dentate gyrus; this is mediated by cAMP/cAMP response elementbinding protein (CREB) signaling (Nakagawa et al., 2002a,b; Fujioka et al., 2004; Sasaki et al., 2007). Thus, PDE4 in the hippocampus is an important component of cellular signaling that mediates memory.

PDE4 has four subtypes (PDE4A-D) that are expressed as at least 25 distinct splice variants (Houslay, 2001; Conti et al., 2003; Cheung et al., 2007; Chandrasekaran et al., 2008; Zhang, 2009). Their differential distributions in brain regions (Cherry and Davis, 1999; Perez-Torres et al., 2000) indicate distinct roles of individual PDE4 subtypes in CNS functions. Limited studies to date have shown that PDE4B is associated with schizophrenia (Millar et al., 2005) and anxiety (Zhang et al., 2008), whereas PDE4D is important for antidepressant activity (Zhang et al., 2002). While lacking clear demonstration, PDE4D appears to be 
the major subtype in mediating memory based on its predominant expression in hippocampal CA1 (Perez-Torres et al., 2000), its major role in cAMP hydrolysis (Zhang et al., 2002) and hippocampal LTP (Rutten et al., 2008), and on the finding that pharmacologically induced overexpression of PDE4D impairs memory (Giorgi et al., 2004). Unfortunately, development of PDE4 inhibitors for therapeutic purposes has been hindered by side effects such as emesis (Robichaud et al., 2001), which appears to be PDE4 subtype specific (Robichaud et al., 2002b).

PDE4 variants are divided into four groups: long-form, shortform, super short-form, and dead-short form PDE4s. Long-form PDE4s are characterized by two unique, upstream conserved regions (UCR1 and UCR2) in the $\mathrm{N}$ terminus; short-form (PDE4B2, D1, and D2) and super short-form PDE4s (PDE4A1, B5, D6, and D10) lack the UCR1 or UCR1 plus a portion of UCR2, respectively; dead short-form PDE4s (such as inactive PDE4A7) (Johnston et al., 2004) lack both UCR1 and UCR2 (Houslay, 2001; O'Donnell and Zhang, 2004; Houslay et al., 2007; Lynex et al., 2008; Zhang, 2009). Long-form and the other PDE4 categories appear to be differentially expressed in brain regions (Perez-Torres et al., 2000; McPhee et al., 2001; Miró et al., 2002). Given that PDE4 variants are targeted to discrete signaling complexes (Houslay, 2010) and that knock-down of specific PDE4 variants using small interfering RNAs (siRNAs) exhibits different cellular actions in vitro (Lynch et al., 2005; Kolosionek et al., 2009), it was of interest to know whether targeting long-form PDE4s, which are most important for cAMP hydrolysis (Baillie et al., 2000), altered memory.

\section{Materials and Methods \\ Animals}

Adult male mice deficient in PDE4D and the wild-type (WT) controls weighing 24-28 g had the same mixed genetic background (C57BL/6 $\times$ $129 /$ Ola). They were generated, bred, and genotyped following the procedures described previously (Hansen et al., 2000; Zhang et al., 2002). Adult male ICR mice weighing 22-26 g were used for experiments using lentiviral vector/microRNA (miRNA) microinfusions. All animals were housed in a temperature-controlled animal facility with a $12 \mathrm{~h}$ light-dark cycle (lights on at 6:00 A.M.). Water and food were freely available in their home cages, except for the radial arm maze test, during which food was restricted to $2 \mathrm{~g}$ per mouse each day after test sessions to maintain body weights at $85-90 \%$ of free-feeding weights. Blind observations were used throughout the experiments, which were carried out from 9:30 A.M. to 4:30 P.M. in a quiet room. All procedures followed the National Institutes of Health (NIH) Guide for the Care and Use of Laboratory Animals (NIH Publications No. 80-23, revised 1996) and were approved by the Animal Care and Use Committee of West Virginia University Health Sciences Center (Morgantown, WV).

\section{Drugs and treatments}

Pentobarbital, ketamine, xylazine, and bromodeoxyuridine (BrdU) were purchased from Sigma-Aldrich; rolipram was purchased from A.G. Scientific. All the drugs were dissolved in saline except for rolipram, which was dissolved in saline containing 5\% dimethyl sulfoxide (DMSO). The injection (i.p.) volume was $10 \mathrm{ml} / \mathrm{kg}$ body weight.

In experiments using WT and PDE4D knock-out (4DKO) mice (Fig. $1 a)$, rolipram $(1.25 \mathrm{mg} / \mathrm{kg})$ or vehicle (5\% DMSO) was given once daily for $26 \mathrm{~d}$; $\mathrm{BrdU}(100 \mathrm{mg} / \mathrm{kg}$ ) was injected (i.p.) once daily on days 10, 12, and 14 of the rolipram treatment period. In experiments using ICR mice treated with lentiviral vectors containing negative control (NC) nucleotides (Invitrogen) or miRNAs targeting long-form PDE4Ds (4DmiRs) (Fig. 1b) (see PDE4D-miRNA knock-down), BrdU (100 mg/kg) was injected three times with a $3 \mathrm{~h}$ interval between injections, followed the next day (day 1 ) by vector microinfusions and rolipram or vehicle, which was given once daily for $16 \mathrm{~d}$. One hour after the injection of rolipram or vehicle on days 15-22 or 10-14, the open field, object recognition, Mor-

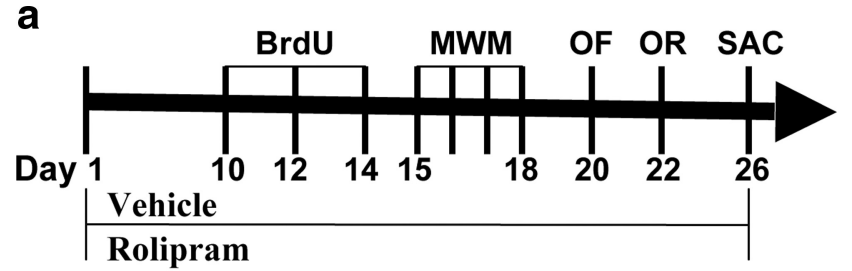

b

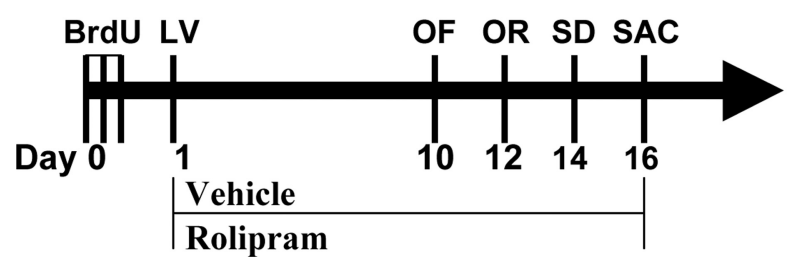

Figure 1. Schedules of drug treatments and tests. $\boldsymbol{a}$, Treatment schedule and test order for mice deficient in PDE4D and their wild-type controls. BrdU (100 mg/kg) was injected (i.p.) once daily on days 10,12 , and 14 after rolipram treatment. Behavioral tests were carried out on days 15-22 ( $1 \mathrm{~h}$ after the injection of rolipram or vehicle). $\boldsymbol{b}$, Treatment schedule and test order for mice treated with lentiviral vectors. BrdU was injected three times with $3 \mathrm{~h}$ intervals. The next day, lentiviral vectors containing 4DmiRs or the NC sequence were infused into bilateral dentate gyri $\left(4 \times 10^{6} \mathrm{TU} / \mu \mathrm{l} / \mathrm{side}\right)$ of the mouse hippocampus. Behavioral tests were carried out on days $10-14$. Rolipram $(1.25 \mathrm{mg} / \mathrm{kg}$ ) or its vehicle (saline containing 5\% DMS0) was injected (i.p.) once daily for $26 \mathrm{~d}(\boldsymbol{a})$ or $16 \mathrm{~d}(\boldsymbol{b})$, after which the animals were killed. MWM, Morris water maze; $0 F$, open field; OR, object recognition; LV, lentiviral vectors; SD, step-down passive avoidance; $S A C$, sacrifice.

ris water maze, and step-down passive avoidance tests were performed (Fig. $1 a, b)$.

\section{Plasmid construction}

Oligonucleotides encoding miRNAs that target long-form PDE4D isoforms (see PDE4D-miRNA knock-down) were designed using Invitrogen BLOCK-iT Pol II miR RNAi expression vector kits and the associated software. Invitrogen $\mathrm{NC}$ sequences were used as the control of PDE4D miRNAs. All the miRNAs and NC sequences were cloned into lentiviral transfer vectors and driven by the phosphoglycerate kinase- 1 promoter. All of the viral vectors contained the enhanced green fluorescence protein (EGFP) as a reporter to track lentivirus-mediated expression using fluorescence microscopy.

\section{Preparation of lentiviral stocks}

The viral particles were produced by transient transfection of HEK293T cells with transfer plasmid containing EGFP and 4DmiR or NC, packaging plasmid pCMV $\Delta$ R-8.92, pMD.G plasmid (vesicular stomatitis virus glycoprotein G envelope), and pRSV-Rev (Rev protein) as described previously (Zala et al., 2004). The supernatant was collected $48 \mathrm{~h}$ later and the virus was precipitated in the presence of polyethylene glycol, resuspended, and purified by centrifugation through a cushion of $20 \%$ sucrose. To ensure comparability among different virus preparations, the virus concentration was determined by real-time PCR to measure the number of integrated copies of HEK293T cells and reported as transducing units (TU; based on the number of integrated copies). After transduction, the vectors were re-suspended in $10 \%$ sucrose/PBS and stored at $-80^{\circ} \mathrm{C}$ until use.

\section{PDE4D-miRNA knock-down}

Lentiviral miRNA-mediated knock-down (Stegmeier et al., 2005) was used to silence PDE4D genes. The sequence for the PDE4D miRNA (shRNA-mir hairpin structure) was 5'-AATGGAGTCACAATCAAGTCAGTTTTGGCCACTGACTGACTGACTTGAGTGACTCCATT-3'. The bold sequence (first $21 \mathrm{nt}$ ) is the antisense target sequence. The final sequence (italics) represents nt 1-8 and 11-21 of the sense target sequence. This miRNA sequence targets nucleotides 642-662 of the rat PDE4D4 coding sequence (GenBank accession no. AF031373), which corresponds to amino acids 214-221 within the UCR1 domain of long-form PDE4D 
isoforms (Bolger et al., 1997); the NC sequence from Invitrogen was 5'-GAAATGTACTGCGCGTGGAGACGTTTTGGCCACTGACTGACGTCTCCACGCAGTACATTT- 3 '. In both 4DmiR and NC sequences, the middle 19 nt (underlined) were constant and came from the miR-155 hairpin loop; the NC was slightly different in the loop region and is predicted not to target any known vertebrate gene based on the demonstration from Invitrogen.

\section{Mouse surgery and lentiviral microinfusions}

All surgery was performed under aseptic conditions. Mice were anesthetized with ketamine $(100 \mathrm{mg} / \mathrm{kg})$ and xylazine $(20 \mathrm{mg} / \mathrm{kg})$ before they were placed in a stereotaxic holder (Stoelting). A 30 gauge infusion cannula (Plastics One) was inserted into the dorsal dentate gyrus (anteriorposterior, $-1.7 \mathrm{~mm}$ from bregma; medial-lateral, $\pm 1.8 \mathrm{~mm}$ from the midline; dorsal-ventral, $-2.0 \mathrm{~mm}$ from the dura) (Paxinos and Franklin, $2001)$ on each side. Lentiviral vectors $\left(4 \times 10^{6} \mathrm{TU} / \mu \mathrm{l}, 1 \mu \mathrm{l} /\right.$ side $)$ containing NC or $4 \mathrm{DmiR}$ were infused at a rate of $0.2 \mu \mathrm{l} / \mathrm{min}$ using a microinjection pump (CMA/Microdialysis). Behavioral experiments were carried out 10-14 d after the infusions. On day 16, mice were perfused transcardially and the brains postfixed and dehydrated before coronal sections $(30 \mu \mathrm{m})$ as described previously (Li et al., 2009). Expression of the miRNAs, which were indicated by EGFP, was examined using fluorescence and confocal microscopy (Zeiss LSM510).

\section{Behavioral experiments}

Three batches of mice (7-10 mice per group) were used for the behavioral and neurochemical tests. One batch of PDE4D-deficient mice and WT littermates was specifically used for examining the effects of PDE4D deficiency on memory using the radial arm maze, given that the test requires food restriction and long-term training (Zhang et al., 2000). Another batch of PDE4D-deficient and WT mice was used for assessing the effects of PDE4D deficiency with or without rolipram treatment on behavior using the open field, object recognition, and water maze tests (Fig. 1a). A subgroup of PDE4D-deficient and WT mice was used for examining xylazine/ketamine-induced anesthesia. The third batch was ICR mice, which were used for testing the effects of PDE4D miRNAs with or without rolipram treatment using open field, object recognition, and step-down passive avoidance tests (Fig. 1b). All the behavioral data were recorded manually by an experimenter blind to the genotype and treatment.

Radial arm maze test. This was performed as described previously (Zhang et al., 2000) with minor modifications. Mice were trained to find food pellets (Fruit Cereal Spins, Great Value, WAL-MART; each was split into eight small pellets) in four randomly selected arms in the eight-arm radial maze $(25 \times 7.5 \times 6 \mathrm{~cm}$ high for each arm and $20 \mathrm{~cm}$ in diameter for the central platform), which was elevated $43 \mathrm{~cm}$ above the floor. The session continued until the mouse collected all four pellets of food or 10 min had passed, whichever came first. Experiments were performed in a well illuminated room that contained several visual cues to aid in spatial localization. Frequencies of working memory errors (i.e., entries into baited arms that had already been visited during the same trial) and reference memory errors (i.e., entries into unbaited arms) were calculated as the number of the respective errors divided by the total number of arm entries. The average exploration time, a measurement of general locomotor activity (Zhang et al., 2000), was calculated as the test duration (i.e., the time spent in collecting all the pellets in the maze) divided by the total number of arms entries. The average of the values from the daily two sessions was calculated for each index.

Object recognition test. The test was carried out as described previously (de Lima et al., 2005). On day 20 or 10 (i.e., 20 or $10 \mathrm{~d}$ after treatment with rolipram or vehicle) (Fig. 1a,b), each mouse was allowed to move freely in an open-field box for $5 \mathrm{~min}$ as habituation; locomotor activity was simultaneously recorded (see Open-field test). Twenty-four hours later, mice were individually placed in the center of the box containing two identical objects (Lego blocks) located in the two diagonal corners. The cumulative time spent in exploring each object was recorded during a $5 \mathrm{~min}$ period. Exploration was defined as actively touching or facing (within 2 $\mathrm{cm}$ toward) the object. On day 22 or 12 ( $24 \mathrm{~h}$ after training), mice were tested for memory using the same procedure except that one of the familiar objects was replaced with a novel object. The time of exploration of each object $\left[T_{\mathrm{f}}\right.$ and $T_{\mathrm{n}}$ for familiar (f) and novel (n) objects, respectively] was recorded for determination of the recognition index (RI): $\mathrm{RI}=T_{\mathrm{n}} /\left(T_{\mathrm{n}}+T_{\mathrm{f}}\right)$. Rolipram was given $1 \mathrm{~h}$ before the test.

Morris water maze test. This was carried out as described previously (Zhang et al., 2008). The apparatus consisted of a circular, plastic pool (95 cm diameter $\times 25 \mathrm{~cm}$ high) located in a well illuminated room with external cues visible from the inside of the pool, which was filled with opaque water $\left(21 \pm 1^{\circ} \mathrm{C}\right)$. A hidden circular platform $(8.5 \mathrm{~cm}$ diameter $\times$ $15.5 \mathrm{~cm}$ high) was submerged $1 \mathrm{~cm}$ under the water in one of four quadrants. The acquisition trials (training to escape to the hidden platform) were carried out for three consecutive days ( 6 trials $\times 2 \mathrm{~d}$ plus 4 trials $\times 1 \mathrm{~d}$ ) starting from day 15 (Fig. 1a). The latency (i.e., the time taken to climb onto the platform) for each mouse was recorded and, $24 \mathrm{~h}$ after the last acquisition trial (i.e., day 18), the probe trial was performed with the platform removed to measure spatial memory. The mouse was allowed to swim for $60 \mathrm{~s}$. The number of entries into and time spent in the target quadrant where the platform was previously located were determined $1 \mathrm{~h}$ after the injection of rolipram $(1.25 \mathrm{mg} / \mathrm{kg})$ or vehicle.

Step-down passive avoidance test. This was performed as described previously (Maurice and Privat, 1997) with minor modifications. The testing apparatus consisted of one side of a Plexiglas chamber $(28 \times 17 \times 25$ $\mathrm{cm}$ high; ENV410B, Med Associates). During the training on day 13 (Fig. $1 b)$, each mouse was placed on a wooden platform $(15.5 \times 8 \times 2.5 \mathrm{~cm}$ high), which was fixed to the grid floor, and subjected to a foot electric shock $(0.4 \mathrm{~mA}$ for $5 \mathrm{~s})$ once it completely descended onto the floor; animals that stepped down within 60 s were immediately trained in another session. Sessions were continued until the mouse stayed on the platform for $60 \mathrm{~s}$; the mouse was then considered to have learned the task. The retention test was performed $24 \mathrm{~h}$ after the training (i.e., day 14) using the same procedure except that no shocks were delivered; the stepdown latency was recorded, with an upper cutoff time of $300 \mathrm{~s}$. Rolipram was given $1 \mathrm{~h}$ before the retention test.

After completion of the behavioral experiments, i.e., $\sim 1 \mathrm{~h}$ after the last injection of rolipram or vehicle, BrdU-treated mice (half of the mice in each group) were perfused and brain coronal sections $(30 \mu \mathrm{m})$ were obtained for immunohistochemical analysis. The other half of the mice in each group were decapitated, their brains removed, and the hippocampus (for noninfused mice) or the punches $(3 \mathrm{~mm}$ in diameter surrounding the injection site) of hippocampal tissues (for vectorinfused mice) were dissected on ice and stored at $-80^{\circ} \mathrm{C}$ before Western blotting.

Open-field test. This was performed as described previously (Zhang et al., 2008) with minor modifications. On day 20 (for 4DKO/WT mice) (Fig. 1a) or $\mathrm{d} 10$ (for $4 \mathrm{DmiR} / \mathrm{NC}$-treated mice) (Fig. $1 b$ ), $1 \mathrm{~h}$ after the injection of rolipram or vehicle the mice were placed individually in a white Plexiglas box $(60 \times 60 \times 15 \mathrm{~cm})$ with the floor divided into four identical squares in a dim room. Line crossings (with all four paws placed into a new square) and rears (with both front paws raised from the floor) were recorded in a 5 min period.

Alpha2 adrenergic receptor-mediated anesthesia. This was performed as described previously (Robichaud et al., 2002a) using 4DKO mice and WT mice treated with rolipram $(1 \mathrm{mg} / \mathrm{kg})$ or $4 \mathrm{DmiR}\left(4 \times 10^{6} \mathrm{TU} / \mu \mathrm{l} /\right.$ side, intra-DG; $2 \mathrm{w}$ before the test). In brief, animals were injected (i.p.) with xylazine $(10 \mathrm{mg} / \mathrm{kg}) / \mathrm{ketamine}(80 \mathrm{mg} / \mathrm{kg}) 15 \mathrm{~min}$ after the injection of rolipram or vehicle. Once the animals became ataxic, they were placed in the supine position in $\mathrm{V}$-shaped metal troughs (covered by paper towels). The duration of anesthesia was determined as the time between the loss and return of the righting reflex; the latter was defined as when animals could right themselves three times within $30 \mathrm{~s}$ after being placed on their backs.

\section{Western blotting}

Hippocampal tissues were processed and Western blot analysis was performed as described previously (Li et al., 2009). Samples (70 $\mu$ g protein each) were separated using SDS-PAGE and then transferred to nitrocellulose membranes. These were then incubated with rabbit antisera against pCREB $\left(\operatorname{Ser}^{133}\right)$, CREB (Millipore), Sox2 (Millipore Bioscience Research Reagents), PDE4A (Bolger et al., 1996) (all these were 1:1000), 
PDE4B (Huston et al., 1997) (1:1500), PDE4D3 (1:500), PDE4D4 (1: 1000), PDE4D5 (1:500; FabGennix for all PDE4 antibodies except for PDE4D3, which was purchased from GeneTex) (Némoz et al., 1996; Bolger et al., 1997), or $\beta$-actin (inner control; 1:1000; Sigma) overnight except for the anti- $\beta$-actin antibody, for which the incubation was $1 \mathrm{~h}$. After washing, the membranes were incubated with Alexa Fluor 700conjugated goat anti-rabbit IgG (1:20,000; Invitrogen) for $30 \mathrm{~min}$. The detection and quantification of specific bands were carried out using a fluorescence scanner (Odyssey Infrared Imaging System, LI-COR Biotechnology) at $700 \mathrm{~nm}$ wavelength. For band stripping, the membranes were incubated with stripping buffer (Millipore Bioscience Research Reagents) for $15 \mathrm{~min}$ at room temperature.

\section{Immunohistochemistry}

This was performed as described previously (Li et al., 2009). In brief, free-floating brain sections were used for immunofluorescent staining of BrdU and its colocalizations; they were incubated for $1 \mathrm{~d}$ with cold PBSplus, which contained rat anti-BrdU (1:200; Abcam), mouse antipolysialic acid neural cell adhesion molecule (PSA-NCAM) (1:200; Millipore Bioscience Research Reagents), rabbit anti-pCREB (1:200), mouse anti-neuronal nuclei (NeuN) (1:1000; Millipore Bioscience Research Reagents), and rabbit anti-S100 $\beta$ antisera (1:100; GeneTex). After rinsing with PBS, the sections were incubated with FITC-conjugated goat anti-rat IgG (1:200; for BrdU labeling in WT and 4DKO mice) or Rhodamine Red-X-conjugated goat anti-rat IgG (1:200; for BrdU labeling in 4DmiR- or NC-treated mice to distinguish EGFP from BrdU-labeled cells), Rhodamine Red-X-conjugated goat anti-mouse IgG (1:200), and Cy5-conjugated goat anti-rabbit IgG (1:400; Jackson ImmunoResearch) in PBS for $2 \mathrm{~h}$. After rinsing, the sections were then mounted with Vectashield medium for fluorescence imaging (Vector Laboratories). Fluorescence analyses were performed using confocal laser microscopy. To determine the percentage of newborn neurons (PSA-NCAM immunopositive) among BrdU-labeled cells and examine pCREB in the newborn cells (i.e., cells labeled for both BrdU and PSA-NCAM), at least 50 BrdU-positive cells in the dentate gyrus were randomly identified in each animal, for which the number of cells in each category was determined.

BrdU-positive cells were counted using a modified stereology protocol (Gould et al., 1999; Li et al., 2009). Every ninth section throughout the entire hippocampus was processed for BrdU immunohistochemistry. All BrdU-labeled cells in the granular cell layer and hilus were counted blindly through a $60 \times$ objective to distinguish individual cells. The number of counted cells were multiplied by 10 and recorded as the total number of labeled cells in the dentate gyrus.

\section{Statistical analysis}

Data shown are expressed as means \pm SEM. All data were analyzed using one-way ANOVA except for the data from the radial arm maze and acquisition training of the water maze, which were analyzed by two-way repeated-measures ANOVA. Newman-Keuls tests were used for post hoc multiple treatment comparisons. Two-tailed unpaired $t$ tests were used for comparisons between genotypes (for radial arm maze) or treatments.

\section{Results}

\section{Enhanced memory in mice deficient in PDE4D}

Mice deficient in PDE4D display enhanced induction of longterm potentiation in hippocampal CA1 slices, but controversially show impaired performance of fear conditioning (Rutten et al., 2008). To clarify this and determine whether PDE4D deficiency enhances hippocampal-dependent memory, we compared behavioral performance of $4 \mathrm{DKO}$ and WT mice in various memory tests, including the eight-arm radial maze, object recognition, and Morris water maze tasks. In the radial arm maze test, both genotypes of mice showed progressive decreases in reference memory errors (i.e., entries into the unbaited arms) during training (Fig. 2a); overall statistical comparisons by two-way ANOVA revealed significant changes in genotype $\left(F_{(1,143)}=4.90, p<\right.$ $0.05)$, time $\left(F_{(13,143)}=5.54, p<0.001\right)$, and interaction of genotype $\times$ time $\left(F_{(13,143)}=2.13, p<0.05\right) .4 \mathrm{DKO}$ mice displayed
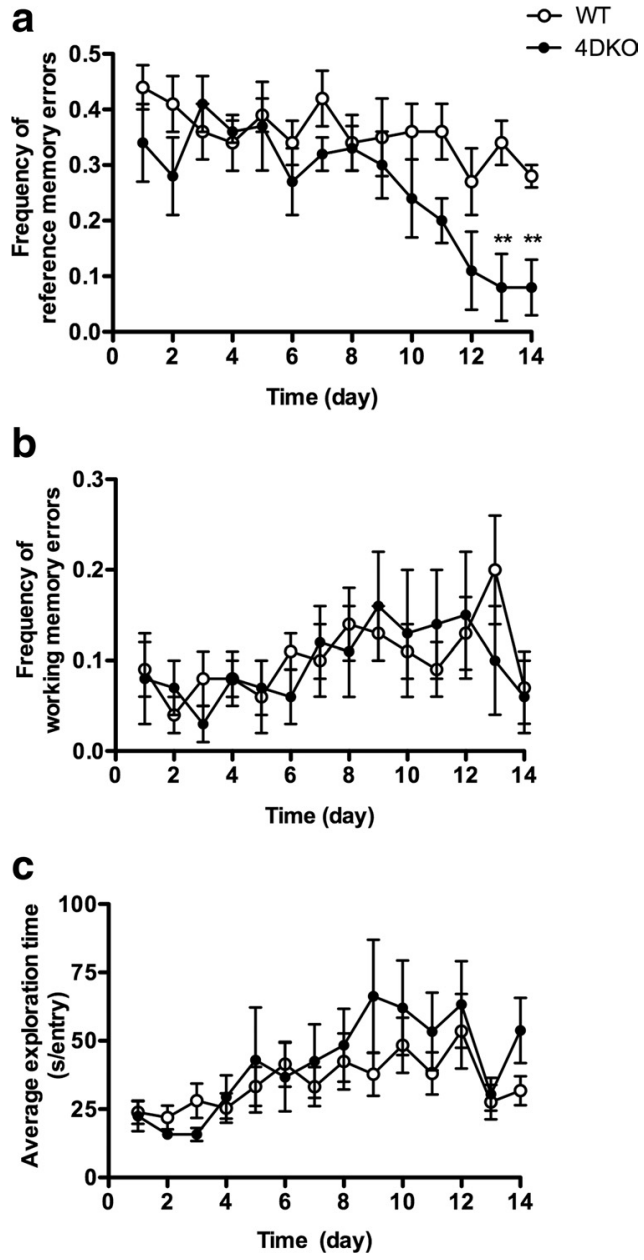

Figure 2. $\quad \boldsymbol{a}-\boldsymbol{c}$, Mice deficient in PDE4D (4DK0) displayed decreases in frequency of reference memory errors $(\boldsymbol{a})$ but not frequency of working memory errors $(\boldsymbol{b})$ or average exploration time (c) in the eight-arm radial maze task. The frequency of reference or working memory errors was calculated as reference memory errors and working memory errors, respectively, divided by the total number of arm entries; the average exploration time was calculated as the test duration divided by the total number of arm entries. Mice were trained for two sessions a day for 14 successive days. Values shown are means \pm SEM; $n=6-7 .{ }^{* *} p<0.01$ versus the WT control.

reduced frequency of reference memory errors compared to WT controls on days 13 and 14 (both $p<0.01$; Student's $t$ tests), indicating enhanced long-term memory (Zhang et al., 2000). In contrast, frequency of working memory errors (Fig. $2 b$ ) and the average exploration time (Fig. $2 c$ ), an index of locomotor activity (Zhang et al., 2000), were not significantly different between the genotypes throughout the training sessions.

The memory-enhancing effect of PDE4D deficiency was verified using the Morris water maze task, which measures hippocampal-dependent memory (Morris et al., 1982; Remondes and Schuman, 2004); rolipram also was added to test the potential involvement of other PDE4 subtypes in memory based on the strategy used previously (Zhang et al., 2002). During the $3 \mathrm{~d}$ acquisition training, all the mice, i.e., vehicle- or rolipramtreated WT and 4DKO mice, displayed progressive decreases in the latency to reach the hidden platform over training trials (Fig. $3 a)$; overall statistical comparisons by two-way ANOVA revealed significant changes in treatment (rolipram and/or gene knockout; $\left.F_{(3,432)}=3.86, p=0.009\right)$, time $\left(F_{(15,432)}=23.56, p<\right.$ $0.0001)$, but not the interaction of treatment $\times$ time $\left(F_{(45,432)}=\right.$ $0.80, p=0.82)$. There was no significant difference between 

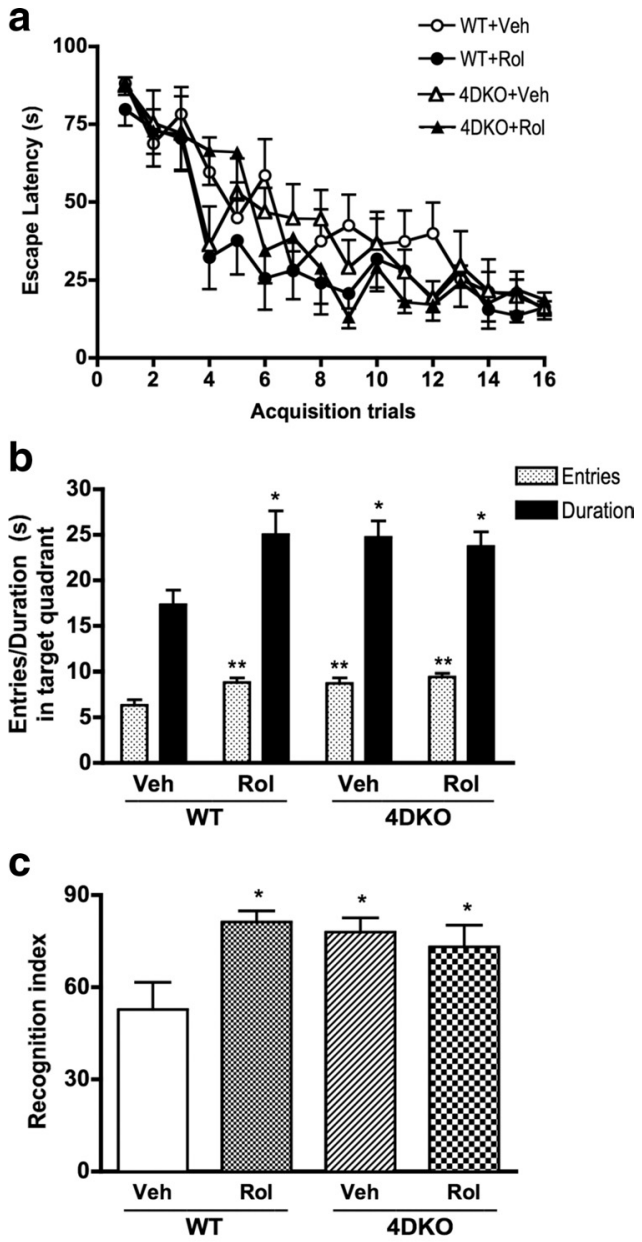

Genotype and treatment

Figure 3. Memory enhancement in mice deficient in PDE4D (4DK0) with or without rolipram (Rol) treatment. $a$, Escape latency during the acquisition trials ( 6 trials $\times 2$ d plus 4 trials $\times 1 \mathrm{~d}$ ) in the water maze test in 4DKO mice and their WT littermates. No difference between $4 D K 0$ and WT or rolipram and vehicle (Veh) in the same genotype. $\boldsymbol{b}$, Increased entries and duration in the target quadrant in the probe trial of the water maze test in 4 DKO mice or WT mice treated with rolipram. c, Increased recognition index in the object recognition test in 4DK0 mice or WT mice treated with rolipram. The recognition index was the exploration time in the novel object, $T \mathrm{n}$, divided by the total exploration time (i.e., $I n$ plus the exploration time in the familiar object, $I f$ ). Rolipram (1.25 mg/kg) or vehicle was injected (i.p.) once daily for $15-18 \mathrm{~d}(\boldsymbol{a}, \boldsymbol{b})$ or $22 \mathrm{~d}(\boldsymbol{c})$ before the test. Values shown are means $\pm \mathrm{SEM} ; n=7-8$; ${ }^{*} p<0.05,{ }^{* *} p<0.01$ versus corresponding WT plus vehicle.

genotypes or treatments. In contrast, in the probe trial test performed $24 \mathrm{~h}$ after the last acquisition trial, WT mice treated with rolipram $(1.25 \mathrm{mg} / \mathrm{kg}$ for $18 \mathrm{~d}$ ) (Fig. $1 a)$ or $4 \mathrm{DKO}$ mice treated with or without rolipram displayed increases in entries $\left(F_{(3,26)}=\right.$ $7.52, p=0.0009)$ and duration $\left(F_{(3,26)}=3.57, p=0.03\right)$ in the target quadrant (Fig. $3 b$ ), as revealed by one-way ANOVA analysis. Post hoc Newman-Keuls tests indicated that rolipram treatment and/or PDE4D deficiency increased both entries $(p<0.01)$ and duration $(p<0.05)$ compared to the control of WT plus vehicle, suggesting enhanced long-term spatial memory. Memory enhancement in $4 \mathrm{DKO}$ mice was not affected by chronic rolipram treatment, indicating a predominant role of PDE4D in the mediation of memory.

The role of PDE4D in memory was further confirmed using the object recognition test in $4 \mathrm{DKO}$ and WT mice treated with or without rolipram. Consistent with the results in the radial arm maze and water maze tests, $4 \mathrm{DKO}$ mice and WT mice treated with rolipram $(1.25 \mathrm{mg} / \mathrm{kg}$ for $22 \mathrm{~d})$ displayed a greater recognition index $\left(F_{(3,27)}=3.95, p=0.02\right)$ in the object recognition test (Fig. 3c); post hoc Newman-Keuls tests indicated that PDE4D deficiency or rolipram treatment increased the recognition index relative to WT mice treated with vehicle $(p<0.05)$. The effect of PDE4D deficiency was not changed by rolipram, supporting the important role of PDE4D in the mediation of memory.

In agreement with the unchanged exploration time in the radial arm maze test, PDE4D deficiency or chronic rolipram treatment alone or in combination did not alter either line crossings or rears in the open-field test (data not shown), suggesting that the memory-enhancing effects were independent of potential changes in general motor activity.

\section{Increased hippocampal neurogenesis in mice deficient in PDE4D}

PDE4 has been shown to be involved in hippocampal neurogenesis (Nakagawa et al., 2002a; Sasaki et al., 2007; Li et al., 2009). To determine whether PDE4D played a role in this process, BrdUpositive cells in the dentate gyrus of the hippocampus were examined $16 \mathrm{~d}$ after the first BrdU injection in $4 \mathrm{DKO}$ and WT mice treated with or without rolipram (Fig. 1a); at this time point, BrdU-positive cells represent the number of survived cells (Schmidt and Duman, 2007). Confocal micrographs indicated that BrdU-positive cells were predominantly localized in the subgranular zone (SGZ) (Fig. 4a), which is consistent with previous reports (Nakagawa et al., 2002a; Li et al., 2009). WT mice treated with rolipram $(1.25 \mathrm{mg} / \mathrm{kg}$ for $26 \mathrm{~d})$ or mice deficient in PDE4D displayed increases in the number of BrdU-labeled cells in the dentate gyrus $\left(F_{(3,12)}=4.12, p=0.03\right)$; post hoc Newman-Keuls tests indicated that PDE4D deficiency or rolipram treatment increased BrdU-positive cells compared to WT controls treated with vehicle $(p<0.05)$ (Fig. $4 b)$. Rolipram had no effect on increased BrdU-positive cells observed in 4DKO mice, indicating that PDE4D is importantly involved in hippocampal neurogenesis.

\section{Phenotypes and colocalizations of BrdU-labeled cells in the dentate gyrus of mice deficient in PDE4D}

BrdU staining was carried out $16 \mathrm{~d}$ after the first BrdU injection in WT and 4DKO mice, by which time newborn cells develop differentiated phenotypes (Kempermann et al., 2003). To examine the phenotype of BrdU-positive cells in the dentate gyrus, double labeling for BrdU and NeuN, a neuronal marker (Mullen et al., 1992; Nakagawa et al., 2002a), or $\mathrm{S} 100 \beta$, a glial marker (Boyes et al., 1986; Nakagawa et al., 2002a), was performed. Analysis by confocal microscopy showed that BrdU-positive cells colocalized with both NeuN- and S100 $\beta$-labeled cells (Fig. $4 c, d$ ), which comprised $\sim 74$ and $17 \%$ of BrdU-positive cells, respectively. Neither rolipram nor $4 \mathrm{DKO}$ altered the percentage of cells maturing into neurons or glial cells (Fig. 4e).

Newborn cells begin to be involved in learning and memory when they are $\sim 2$ weeks of age (Shors et al., 2001; BruelJungerman et al., 2005). Newborn neurons (including neuroblast types I and II and immature neurons) in the dentate gyrus express PSA-NCAM 2 weeks before they mature into granular neuronal cells (Nakagawa et al., 2002b; Encinas et al., 2006). To determine the proportion of newborn neurons and pCREB-expressing cells among BrdU-positive cells and newborn neurons, respectively, coexpression of BrdU, PSA-NCAM, and pCREB was examined using triple staining $16 \mathrm{~d}$ after the first BrdU injection. In WT mice treated with vehicle, $\sim 85 \%$ of BrdU-labeled cells became newborn neurons, as evidenced by colocalization with PSANCAM (Fig. $4 f, g$ ); 92\% of the BrdU-labeled newborn neurons 

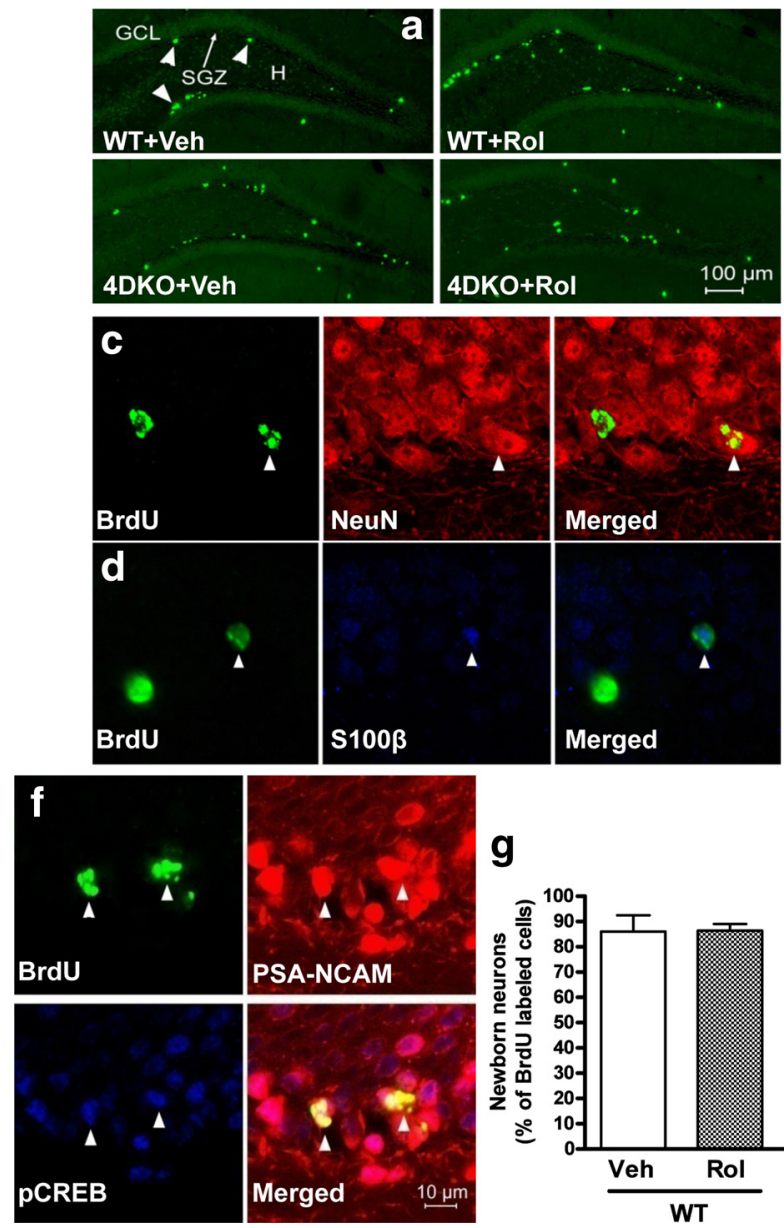

g

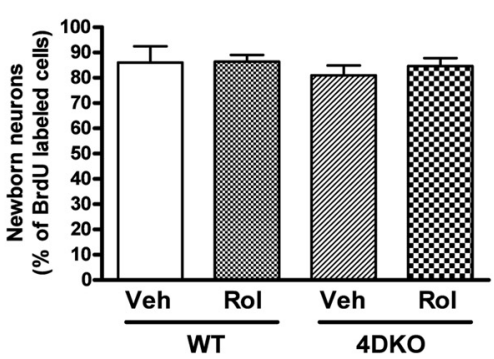

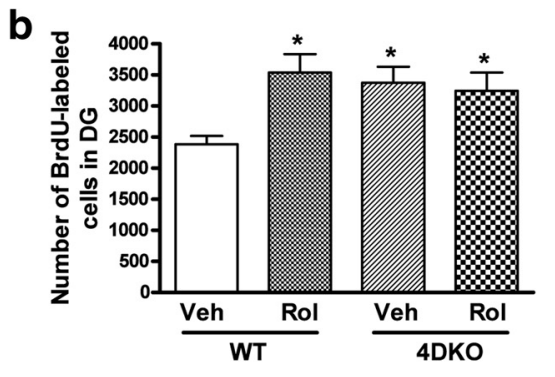

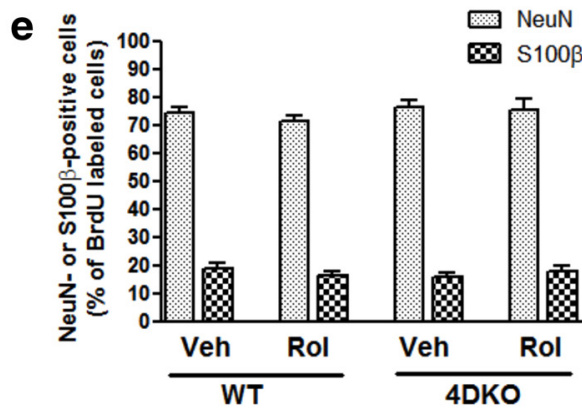

h

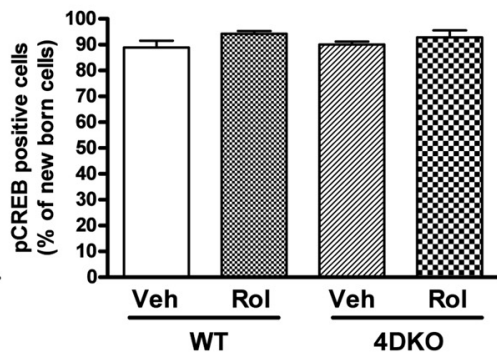

Figure 4. Cells labeled for BrdU and/or NeuN, S100 $\beta$, PSA-NCAM, or pCREB in the hippocampal dentate gyrus in mice deficient in PDE4D (4DK0) with or without rolipram (Rol) treatment. $\boldsymbol{a}, \boldsymbol{b}$, Confocal micrographs $(\boldsymbol{a})$ and quantification $(\boldsymbol{b})$ of BrdU-labeled cells (green) in the dentate gyrus from 4DKO or WT mice with or without rolipram. The majority of BrdU-labeled cells were located in the SGZ and hilus (H). While 4DKO and rolipram-treated WT mice displayed increases in BrdU-positive cells, rolipram did not alter BrdU-positive cells in 4DKO mice. $\boldsymbol{c}, \boldsymbol{d}$, Phenotype of BrdU-positive cells in the dentate gyri of 4DKO mice. Confocal micrographs of cells double-labeled for BrdU (green; left) and the neuronal marker NeuN (red; middle and top) or the glial marker $S 100 \beta$ (blue; middle and bottom). $e$, Unaltered percentages of neuronal and glial cells labeled by BrdU in the dentate gyri of $4 D K 0$ mice with or without rolipram treatment. $\boldsymbol{f}$, Representative confocal micrographs of cells triple-labeled for BrdU, the newborn neuron marker PSA-NCAM (red), and pCREB (blue) in the dentate gyri of 4DKO mice, which indicate colocalization of PSA-NCAM and pCREB in developing BrdU-positive cells. $\boldsymbol{g}$, Unaltered percentages of newborn neurons labeled by PSA-NCAM in BrdU-positive cells in the dentate gyrus from WT or 4DKO mice following rolipram or vehicle treatment. PSA-NCAM-labeled cells comprised $84.5 \%$ of BrdU-positive cells. $\boldsymbol{h}$, Unaltered percentages of $p$ CREB-labeled cells in newborn neurons in the dentate gyrus from WT or 4DK0 mice following rolipram or vehicle treatment. pCREB-labeled cells comprised $91.5 \%$ of cells double labeled for PSA-NCAM and BrdU. Mice were given rolipram (1.25 mg/kg, i.p.) or vehicle once daily for $26 \mathrm{~d}$; BrdU (100 mg/kg) was injected (i.p.) once daily on days 10,12 , and 14 . On day $26,1 \mathrm{~h}$ after the rolipram injection, mice were perfused and frozen brain sections prepared for immunohistochemistry. Bars shown are means $\pm S E M ; n=4 ;{ }^{*} p<0.05$ versus WT plus vehicle (Veh).

expressed pCREB (Fig. $4 f, h)$. These percentages were not changed by either rolipram treatment or PDE4D deficiency $\left[F_{(3,12)}=0.33\right.$, $p=0.80$ for newborn neurons (Fig. $4 g$ ); $F_{(3,12)}=1.40, p=0.29$ for pCREB (Fig. 4h)], indicating that the increase in neurogenesis was not caused by increased newborn neurons; pCREB may play an important role in survival of newborn neurons in the hippocampal dentate gyrus. Accordingly, we examined potential changes in progenitor cells that reside in the subgranular zone, proliferate and migrate into the granular cell layer, and mature into neurons and other cell types in the hippocampal dentate gyrus (Duman et al., 2001; van Praag et al., 2002).

\section{Increased pCREB and Sox 2 in the hippocampus of mice deficient in PDE4D}

Given that cAMP/CREB signaling is critical for memory (Abel and Kandel, 1998; Barco et al., 2003; Monti et al., 2006) and neurogenesis (Nakagawa et al., 2002a,b; Li et al., 2009) and is present in newborn neurons, it was of interest to know whether PDE4D deficiency altered pCREB in the hippocampus. Expression of Sox2, a mitotic neural progenitor cell marker (Graham et al., 2003; Episkopou, 2005), was also examined to determine proliferation of progenitor cells in the hippocampus. Confocal microscopic analysis showed that pCREB was predominantly expressed in the granular cell layer (GCL) and subgranular zone (SGZ) of the dentate gyrus (Fig. $5 a)$. Mice deficient in PDE4D or WT mice treated with rolip$\mathrm{ram}(1.25 \mathrm{mg} / \mathrm{kg}, 26 \mathrm{~d})$ displayed increases in pCREB $\left(F_{(3,12)}=\right.$ $4.25, p=0.03)$ (Fig. $5 b)$ and Sox2 $\left(F_{(3,12)}=3.84, p=0.04\right)$ (Fig. 5c) in the hippocampus; post hoc Newman-Keuls tests indicated that PDE4D deficiency or chronic rolipram treatment increased expression of pCREB and Sox 2 in the hippocampus compared to WT mice treated with vehicle $(p<$ $0.05)$. Rolipram did not alter the effect of PDE4D deficiency on expression of pCREB and Sox2. In contrast to pCREB, CREB levels were not altered by PDE4D deficiency or rolipram treatment $\left(F_{(3,12)}=0.3, p=0.83\right.$; data not shown $)$. These 

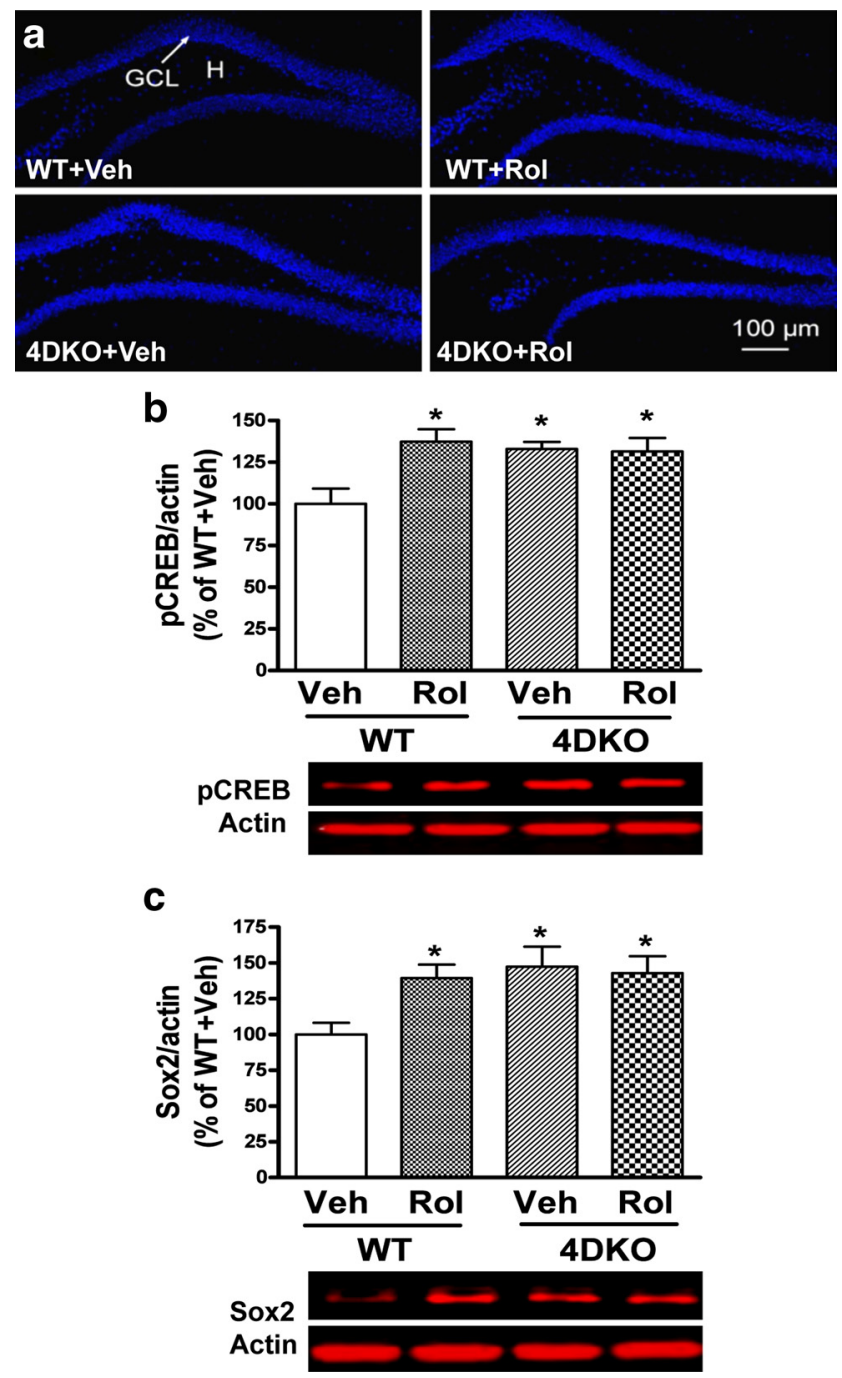

Figure 5. Effects of PDE4D deficiency on levels of $p C R E B$ and Sox 2 in the hippocampus in the presence or absence of rolipram (Rol). $\boldsymbol{a}$, Representative confocal micrographs of pCREBpositive cells (blue) in the dentate gyrus from mice deficient in PDE4D (4DKO) or WT controls following chronic treatment with rolipram or vehicle. $\boldsymbol{b}, \boldsymbol{c}$, Changes in expression of pCREB $(\boldsymbol{b})$ and Sox2 (c) in the hippocampus from WT or 4DK0 mice treated repeatedly with rolipram or vehicle. Bottom panels are representative immunoblots of pCREB or Sox2 detected by Western blotting; top panels are the corresponding quantification. Whereas $4 D K 0$ and rolipram-treated WT mice displayed increases in pCREB-positive cells and expression of pCREB and Sox2, the effects of PDE4D deficiency were not altered by chronic rolipram treatment. Rolipram (1.25 $\mathrm{mg} / \mathrm{kg}$ ) was injected (i.p.) once a day for $26 \mathrm{~d}$; $1 \mathrm{~h}$ after the last injection, mice were killed and the brains prepared for immunohistochemistry or hippocampi were dissected for immunoblot analysis. Bars shown are means $\pm \mathrm{SEM} ; n=4 ;{ }^{*} p<0.05$ versus corresponding WT plus vehicle (Veh)

results suggest that $\mathrm{PDE} 4 \mathrm{D}$ is important in rolipram-induced proliferation of mitotic neural progenitor cells, which involves activation of cAMP/CREB signaling in the hippocampus ( $\mathrm{Li}$ et al., 2009).

\section{Downregulation of PDE4D variants by PDE4D-miRNAs in the mouse hippocampus}

To determine the role of long-form PDE4D variants in memory, lentiviral vectors harboring either 4DmiRs (miRNAs designed to target long-form PDE4Ds) or the NC sequence were microinfused bilaterally into the hippocampal dentate gyri (Fig. $6 a, b$, left). The vectors contained the EGFP sequence, which permitted visualization of the infection in the dentate gyrus $16 \mathrm{~d}$ after len- tiviral infusions. EGFP-positive cells were mainly located in the GCL and SGZ, although moderate expression of EGFP was observed in the projections extending into the inner portion of the CA3 subregion (Fig. $6 a, b$, middle and right). These results suggest that $4 \mathrm{DmiR}$ and $\mathrm{NC}$ were well expressed in the dentate gyrus under the conditions used. One-way ANOVA of the immunoblotting data (Fig. $6 c$ ) revealed significant changes in all the variants examined except for PDE4B4 (4D3: $F_{(3,12)}=5.33, p=0.01$; 4D4: $F_{(3,12)}=4.39, p=0.03 ; 4 \mathrm{D} 5: F_{(3,12)}=5.57, p=0.01 ; 4 \mathrm{~A} 5$ : $F_{(3,12)}=8.19, p=0.003 ; 4 \mathrm{~B} 1: F_{(3,12)}=3.95, p=0.04 ; 4 \mathrm{~B} 4:$ $F_{(3,12)}=0.27, p=0.85$ ) (Fig. 6d,e). Post hoc Newman-Keuls tests indicated that, compared to $\mathrm{NC}, 4 \mathrm{DmiR}$ alone decreased PDE4D4 $(p=0.01)$ and 4D5 $(p<0.05)$ but did not alter expression of any of the other PDE4 variants detected (i.e., PDE4D3, $4 \mathrm{~A} 5,4 \mathrm{~B} 1$, and $4 \mathrm{~B} 4)$ in punches of hippocampi; rolipram treatment (1.25 mg/kg, 16 d) alone decreased expression of PDE4D4, 4D5, 4B1 (all $p<0.05$ ), and 4A5 $(p<0.01)$ but increased expression of PDE4D3 $(p<0.05)$ and did not alter 4B4, relative to the vehicle (plus NC) control (Fig. $6 c-e$ ). In addition, rolipram did not alter 4DmiR-induced decreases in expression of PDE4D4 and 4D5.

\section{Memory enhancement produced by downregulation of PDE4D variants in the mouse hippocampus}

To determine whether knock-down of long-form PDE4Ds mimicked the ability of PDE4D deficiency to enhance memory, we microinfused $4 \mathrm{DmiR}$ or NC into bilateral dentate gyri $12-14 \mathrm{~d}$ before object recognition and step-down passive avoidance tests (Fig. 1b). Given the equivalent potency of rolipram for inhibition of all PDE4 subtypes/isoforms (MacKenzie and Houslay, $2000)$, rolipram $(1.25 \mathrm{mg} / \mathrm{kg})$ was coadministered with $4 \mathrm{DmiR}$ to determine the potential involvement of other PDE4 variants in memory. If miRNA-targeted long-form PDE4Ds are important, inhibition by rolipram of the remaining PDE4s, including PDE4A, PDE4B, and nonlong form PDE4Ds, in the brain of 4DmiR-treated mice should not further enhance memory; otherwise, the memory-enhancing effect of long-form PDE4D knock-down would be potentiated in the presence of rolipram. The results showed that the former was the case. Specifically, one-way ANOVA revealed increased recognition index $\left(F_{(3,31)}=\right.$ $5.59, p=0.004)$ (Fig. $7 a)$ and retention latency $\left(F_{(3,31)}=3.57\right.$, $p=0.02$ ) (Fig. $7 b$ ) $24 \mathrm{~h}$ after training in mice treated with $4 \mathrm{DmiR}$ and/or rolipram in the object recognition and passive avoidance tests, respectively. Post hoc Newman-Keuls tests indicated that $12 \mathrm{~d}$ after single $4 \mathrm{DmiR}$ infusions or daily rolipram injections, the recognition index was increased in the object recognition test compared to NC plus vehicle ( $p<0.05$ for $4 \mathrm{DmiR}$ and $p<0.01$ for rolipram) (Fig. 7a). Consistent with this, in the step-down passive avoidance task, mice treated with $4 \mathrm{DmiR}$ or rolipram displayed increases in latency to step down from the platform during the retention test performed $24 \mathrm{~h}$ after initial training on day 14 compared to mice treated with NC plus vehicle $(p<0.05)$ (Fig. $7 b$ ). In addition, $4 \mathrm{DmiR}$ or rolipram decreased the number of trials $(p=0.02)$ required for reaching the criteria (staying on the platform for $60 \mathrm{~s}$ ) during the training (data not shown). In both cases, the effects of $4 \mathrm{DmiR}$ on memory performance were not changed in the presence of rolipram. The effects of $4 \mathrm{DmiR}$ and/or rolipram on memory performance were not associated with general motor activity given that the treatment did not alter line crossings $\left(F_{(3,31)}=0.12, p=0.95\right)$ or rears $\left(F_{(3,31)}=0.18\right.$, $p=0.91)$ in the open-field test $10 \mathrm{~d}$ after the lentiviral infusions (data not shown). 

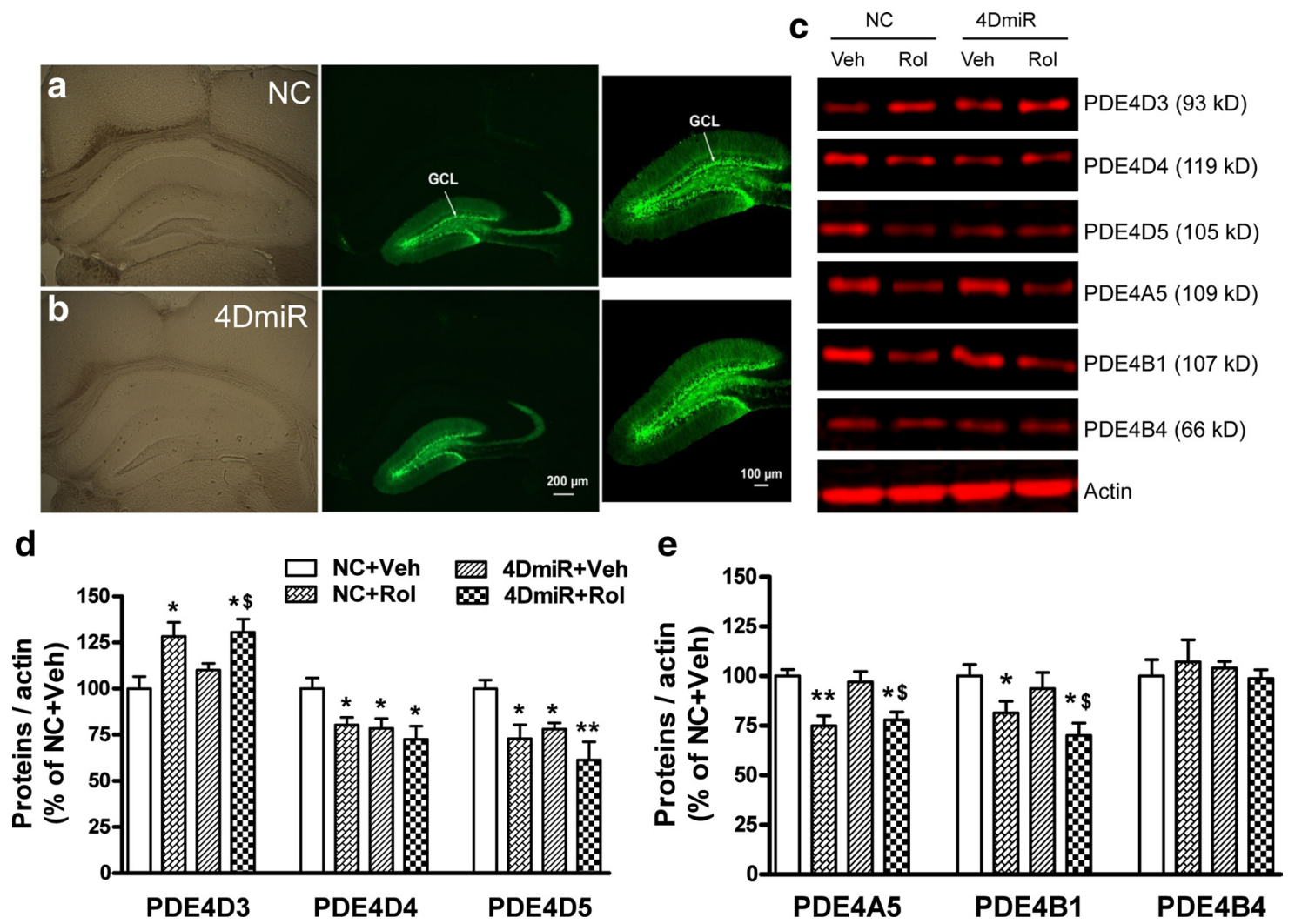

Figure 6. Effects of the lenti-PDE4D-miRNA (4DmiR) on expression of PDE4 splice variants in the mouse hippocampus, with or without rolipram (Rol) treatment. $\boldsymbol{a}, \boldsymbol{b}$, Representative micrographs of injection sites in the hippocampus (left) and expression of NC ( $\boldsymbol{a})$ and $4 \mathrm{DmiR}(\boldsymbol{b})$, indicated by EGFP (green; middle and right panels; the right panels are magnifications of the middle panels), in the dentate gyrus $16 \mathrm{~d}$ following bilateral microinfusions of the lentiviral vectors into the dentate gyri ( $4 \times 10^{6} \mathrm{TU} / \mu \mathrm{l}, 1 \mu \mathrm{l}$ per side). $\mathrm{c}$, Representative immunoblots of PDE4D3, 4D4, 4D5, 4A5, 4B1, and $4 B 4$ detected by Western blotting using punched hippocampal tissues ( $3 \mathrm{~mm}$ in diameter surrounding the injection hole in the hippocampus) from mice treated with NC or 4DmiR, with or without rolipram treatment $(1.25 \mathrm{mg} / \mathrm{kg}$ ) that was injected (i.p.) once daily for $16 \mathrm{~d}$. $\boldsymbol{d}, \boldsymbol{e}$, Quantification of PDE4D3-5 (d) and PDE4A/B (e) from the respective immunoblots (c). Bars shown are means $\pm \mathrm{SEM} ; n=4 ;{ }^{*} p<0.05,{ }^{* *} p<0.01$ versus corresponding NC plus vehicle (Veh); ${ }^{\$} p<0.05$ versus corresponding 4 DmiR plus vehicle.

Increases in pCREB and neurogenesis in the hippocampus produced by downregulation of PDE4D variants

After completion of behavioral experiments, mice were killed to determine the effects of $4 \mathrm{DmiR}$ on $\mathrm{PCREB}$ and hippocampal neurogenesis. One-way ANOVA revealed increases in pCREB levels in the hippocampus $\left(F_{(3,12)}=4.60, p=0.02\right)$ (Fig. $\left.7 c\right)$ and BrdU-positive cells in the dentate gyrus $\left(F_{(3,12)}=4.43, p=0.03\right)$ (Fig. $7 d, e) 16 \mathrm{~d}$ after viral microinfusions or daily rolipram treatment (i.e., $17 \mathrm{~d}$ after BrdU injections) (Fig. 1b). Newman-Keuls tests indicated that $4 \mathrm{DmiR}$ or rolipram increased pCREB levels and the number of BrdU-labeled cells in the hippocampus compared to NC (plus vehicle; both $p<0.05$ ). Rolipram did not alter 4 DmiR-induced increases in pCREB or BrdU-labeled cells compared to corresponding $4 \mathrm{DmiR}$ plus vehicle (Fig. $7 c-e)$. In contrast, none of the treatments altered CREB levels $\left(F_{(3,12)}=1.03\right.$, $p=0.41$; data not shown). These results suggest that long-form PDE4D variants such as PDE4D4 and PDE4D5 are involved in cAMP/CREB signaling and hippocampal neurogenesis.

\section{Absence of emetic-like response in lentiviral}

\section{PDE4D-miRNAs-treated mice}

Emesis is the major side effect of PDE4 inhibitors (Robichaud et al., 2001, 2002a; Dyke and Montana, 2002). It appears to be associated with PDE4D (Robichaud et al., 2002b). To determine whether long-form PDE4D variants in the hippocampus are involved in emesis, we examined the effects of $4 \mathrm{DmiR}$ on xylazine/ ketamine-induced anesthesia, a surrogate approach to assessing emetic response in nonvomiting species (Robichaud et al., 2001, 2002a). While both 4DKO mice and rolipram-treated WT mice displayed shortened duration of anesthesia $\left(F_{(3,43)}=5.02, p=\right.$ 0.004; Newman-Keuls tests, $p<0.01$ for $4 \mathrm{DKO}$ and $p<0.05$ for rolipram) (Fig. 8), 4DmiR-treated WT mice did not differ from the vehicle-treated controls, suggesting that downregulation of long-form PDE4Ds in the hippocampus may not cause emesis.

\section{Discussion}

PDE4 plays an important role in the mediation of memory. Pretreatment with the prototypic PDE4 inhibitor rolipram, either acutely or chronically, reverses memory deficits induced by a variety of manipulations (Egawa et al., 1997; Imanishi et al., 1997; Zhang and O'Donnell, 2000; Zhang et al., 2000, 2004, 2005; Bourtchouladze et al., 2003). Consistent with these, chronic treatment with rolipram enhanced memory in untreated mice; this is supported by findings in previous studies (Villiger and Dunn, 1981; Romano et al., 1996; Barad et al., 1998). However, it is not clear which PDE4 subtype is important in mediating memory, primarily because of the lack of highly selective inhibitors of individual PDE4 subtypes. Using approaches of gene knock-out and miRNA-induced gene knock-down, we have demonstrated that PDE4D, in particular its long-form isoforms, plays an important role in the mediation of memory and hippocampal neurogenesis. Targeting long-form PDE4Ds appears to be a better approach to enhancing memory given that it was not involved in the emetic response.

Results from our previous studies have provided a link between PDE4D and memory (Zhang et al., 2004, 2005), but there 
a

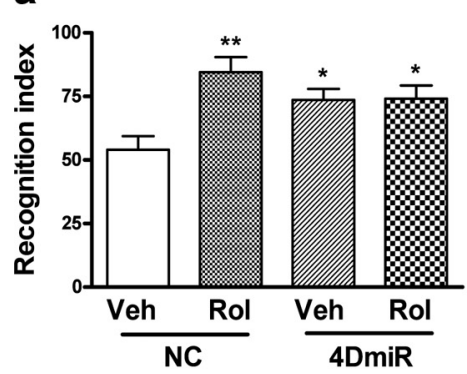

b

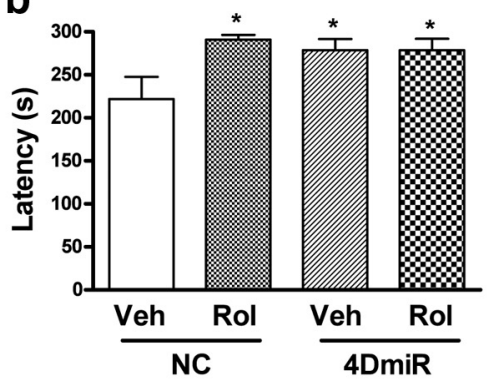

C

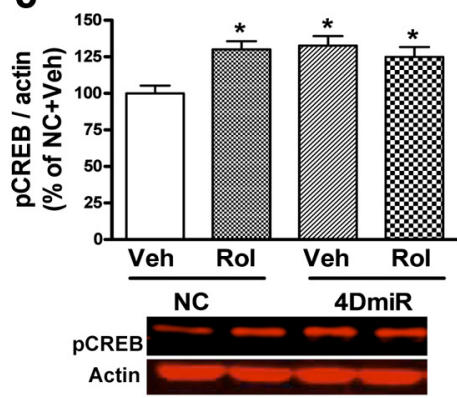

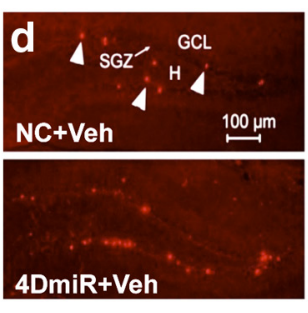

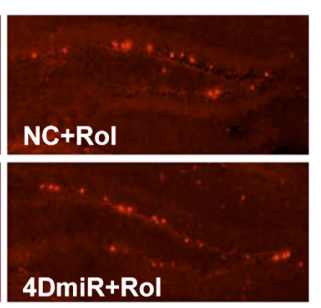

e

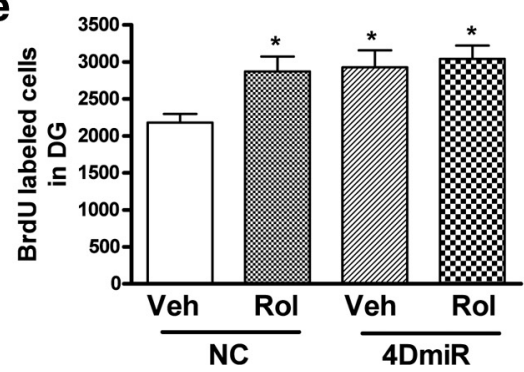

Figure 7. Effects of lenti-PDE4D-miRNAs (4DmiR) on memory and hippocampal pCREB and neurogenesis, with or without rolipram (Rol) treatment in mice. $\boldsymbol{a}, \boldsymbol{b}$, Memory performance of mice treated with $4 \mathrm{DmiR}$ or NC alone or in combination with rolipram in the object recognition test $(\boldsymbol{a})$ and step-down passive avoidance test $(\boldsymbol{b})$. 4DmiR or rolipram alone enhanced long-term memory, as indicated by increased recognition index and retention latency, respectively, tested $24 \mathrm{~h}$ after training. c, Increased expression of pCREB in the hippocampus from mice treated with 4DmiR or rolipram alone or in combination. Bottom panels are representative immunoblots of pCREB detected by Western blotting; top panels are quantification. $\boldsymbol{d}, \boldsymbol{e}$, Confocal micrographs (d) and quantification (e) of BrdU-labeled cells (red) in the dentate gyrus from mice treated with $4 \mathrm{DmiR}$ or NC with or without rolipram treatment. BrdU ( $100 \mathrm{mg} / \mathrm{kg})$ was injected (i.p.) three times with $3 \mathrm{~h}$ intervals. Twenty-four hours after the first injection of BrdU, $4 \mathrm{DmiR}$ or NC was microinfused into bilateral dentate gyri using a single dose of $4 \times 10^{6} \mathrm{TU} / \mu \mathrm{l} / \mathrm{side}$, after which rolipram $(1.25 \mathrm{mg} / \mathrm{kg})$ or its vehicle was injected (i.p.) once daily for 12 or $14 \mathrm{~d}$ before the object recognition or passive avoidance test, respectively. One hour after the injection of rolipram on day 16 , mice were killed and their brains prepared for immunohistochemistry or their hippocampi dissected and punched for immunoblot analysis. Bars are means $\pm \operatorname{SEM} ; n=8-10(\boldsymbol{a}, \boldsymbol{b})$ or $4(\boldsymbol{c}-\boldsymbol{e}) ;{ }^{*} p<0.05,{ }^{* *} p<0.01$ versus corresponding NC plus vehicle (Veh). H, Hilus.

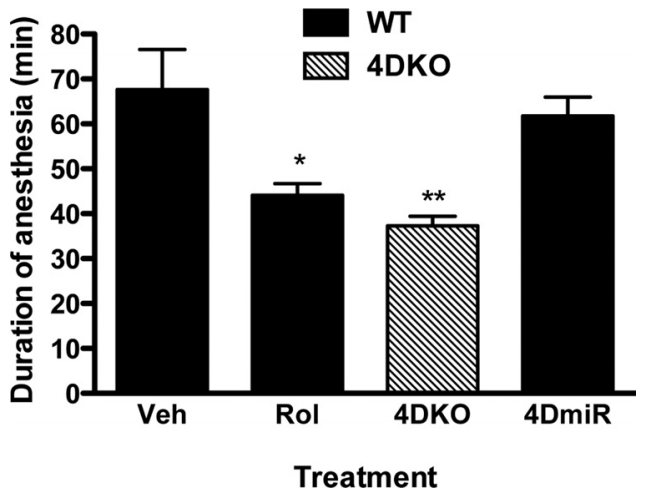

Figure 8. Mice deficient in PDE4D (4DK0) or treated with rolipram (Rol) or 4DmiRs displayed different effects on xylazine/ketamine-induced anesthesia. Lentiviral $4 \mathrm{DmiR}\left(4 \times 10^{6} \mathrm{TU} / \mu \mathrm{l} /\right.$ side) was infused into bilateral dentate gyri 2 weeks before the test; xylazine $(10 \mathrm{mg} / \mathrm{kg})$ and ketamine $(80 \mathrm{mg} / \mathrm{kg}$ ) were injected (i.p.) $15 \mathrm{~min}$ after rolipram $(1 \mathrm{mg} / \mathrm{kg}$ ) or vehicle. Once animals became ataxic, they were placed on their backs until they righted themselves three times within $30 \mathrm{~s}$. The duration of anesthesia was determined as the time between the loss and return of the righting reflex. Bars are means $\pm \mathrm{SEM} ; n=10-16 ;{ }^{*} p<0.05,{ }^{* *} p<0.01$ versus vehicle (Veh).

has been lack of evidence for the role of PDE4D in memory. Here we demonstrated that mice deficient in PDE4D displayed enhanced hippocampal-dependent memory, in particular longterm memory, in different tests, suggesting that PDE4D is important in memory. This was confirmed by administration of rolipram in PDE4D-deficient mice, a strategy that has been used to verify the contribution of PDE4D to a specific behavioral profile (Zhang et al., 2002). If PDE4D is not important, inhibition by rolipram of the remained PDE4 subtypes (primarily PDE4A and
PDE4B) in the brain of PDE4D-deficient mice should potentiate the memory-enhancing effect. However, this was not the case; rolipram did not alter memory in PDE4D-deficient mice, indicating a predominant role of PDE4D in mediating memory. The importance of PDE4D for memory appears to be consistent with the findings that mice deficient in PDE4B do not exhibit changes in memory (Siuciak et al., 2008; Zhang et al., 2008) and is supported by several other studies. First, selective PDE4D allosteric modulators not only reverse scopolamine-induced memory impairment but also enhance memory on their own in mice (Burgin et al., 2010). Second, hippocampal LTP is enhanced in PDE4Ddeficient mice, although amygdala-dependent, fear-conditioning memory is unexpectedly impaired (Rutten et al., 2008). Third, increased expression of PDE4D induced by high doses of PDE4 inhibitors impairs memory (Giorgi et al., 2004). Nevertheless, a potential role of PDE4A in memory cannot be excluded given that this subtype is also highly expressed in the hippocampus (Cherry and Davis, 1999; Perez-Torres et al., 2000; McPhee et al., 2001).

The role of PDE4D in memory appears to be attributed to its regulation of CAMP/CREB signaling. Consistent with the observations in WT mice treated with rolipram, mice deficient in PDE4D also concurrently displayed increased PCREB in the hippocampus and enhanced memory in tests for hippocampaldependent memory; the former is consistent with increases in cAMP concentrations in brain tissues and profound decreases in PDE4 activity in the hippocampus of PDE4D-deficient mice (Zhang et al., 2002). These findings and rolipram-unaltered pCREB in 4DKO mice suggest that PDE4D is an important PDE4 subtype responsible for memory mediated by cAMP/CREB sig- 
naling, although further studies using PDE4A-deficient mice are required to establish the role of $\mathrm{PDE} 4 \mathrm{~A}$.

PDE4-mediated CAMP/CREB signaling plays a critical role in the regulation of adult neurogenesis (Nakagawa et al., 2002a,b; Sasaki et al., 2007; Li et al., 2009), which is associated with learning and memory (Shors et al., 2001; van Praag et al., 2002). Consistent with this, chronic treatment with rolipram at a dose that increased pCREB and enhanced memory increased BrdUpositive cells in the dentate gyrus of WT mice 2 weeks after BrdU injections, at which time BrdU-labeled cells survived instead of proliferated (Schmidt and Duman, 2007). The neurogenic effect of rolipram was mimicked by PDE4D deficiency, which increased BrdU-positive cells (primarily survival) in the dentate gyrus to levels similar to those seen following chronic rolipram treatment. Given that rolipram did not alter the neurogenic effect of PDE4D deficiency and that mice deficient in PDE4B display only a slight increase in cell proliferation but not in survival of neurons (Zhang et al., 2008), PDE4D appears to be the major PDE4 subtype responsible for hippocampal neurogenesis.

Rolipram has been shown to increase hippocampal neurogenesis by increasing amplifying neural progenitors (ANPs) (Li et al., 2009), which divided into neuroblasts and eventually mature neurons during the postmitotic phase (Encinas et al., 2006). At the dose that increased hippocampal neurogenesis and PCREB, rolipram increased expression of Sox 2 , a marker of neural progenitor cells (Graham et al., 2003; Episkopou, 2005), in the hippocampus but did not change the phenotype of BrdU-positive cells in the present and previous studies (Malberg et al., 2000; Nakagawa et al., 2002b; Li et al., 2009). Similarly, PDE4D deficiency also increased hippocampal Sox2, which was not altered by rolipram; it did not change the proportion of newborn neurons among BrdU-positive cells. Therefore, PDE4D deficiency increases hippocampal neurogenesis most likely by acting on ANPs instead of directly targeting the postmitotic phase of progenitor cells.

The major challenge of gene knock-out techniques is gene deficiency throughout the whole body, which may lead to abnormal development (Jin et al., 1999) and emesis (Robichaud et al., $2002 \mathrm{~b}$ ). To overcome these, we used miRNAs, one of the RNAi techniques for gene silencing (Zeringue and Constantine-Paton, 2004; Cullen, 2005), to knock down the long-form PDE4Ds, given that long-form PDE4Ds are: (1) highly regulated by PKA and ERK and contain binding sites for protein-protein interactions (Houslay, 2010); (2) important for intracellular cAMP hydrolysis (Baillie et al., 2000); and (3) relatively highly expressed in the hippocampus (Miro et al., 2002; Richter et al., 2005). Gene silencing of PDE4 splice variants has been achieved in vitro by using siRNAs targeting a specific variant of PDE4B or PDE4D (Lynch et al., 2005; Li et al., 2006). While it is difficult to target individual PDE4D isoforms because of their high homologies, we designed a miRNA sequence to target nucleotides 642-662 of the PDE4D coding sequence, which corresponds to amino acids 214221 within the UCR1 domain of long-form PDE4D isoforms (Bolger et al., 1997). We used lentivirus as the vector for miRNAs given that lentiviral vector-mediated miRNAs produce stable, long-term, and neuron-specific gene suppression (Dull et al., 1998; Zufferey et al., 1998; Stegmeier et al., 2005; Schratt et al., 2006; Grillo et al., 2007), in contrast to synthetic siRNAs (Zentilin and Giacca, 2004). As indicated by EGFP, lentiviral miRNAs were well expressed in the GCL of the dentate gyrus; long-form PDE4D4 and PDE4D5 were selectively downregulated in the hippocampus, leading to increases in hippocampal neurogenesis and pCREB levels and enhancement of memory. While the other long-form PDE4Ds (i.e., PDE4D7-9, 11) were not examined because of the lack of specific antibodies, the results suggest that at least the PDE4D4/5 variants are importantly involved in these processes. Further studies using similar gene silencing techniques are required to determine the role of other long-form PDE4Ds and variants of other PDE4 subtypes, in particular PDE4A5 and PDE4A10, that are highly expressed in the hippocampus (McPhee et al., 2001; D'Sa et al., 2005) in memory.

It was noted that chronic rolipram treatment differentially altered PDE4 variants, i.e., decreased expression of PDE4D4, D5, $\mathrm{A} 5$, and $\mathrm{B} 1$, increased expression of PDE4D3, but did not alter PDE4B4 in the hippocampus. These results are consistent with previous findings (Dlaboga et al., 2006). Regardless, the effects of rolipram on memory, pCREB, and neurogenesis did not differ from those of combined rolipram and PDE4D-miRNAs, supporting an important role for PDE4D4 and PDE4D5 in these processes. Again, the role of other PDE4 variants such as PDE4A5 and PDE4A10 cannot be excluded given that they are highly expressed in the hippocampus (McPhee et al. 2001; D'Sa et al., 2005). Other long-form PDE4Ds may also contribute to the effects of $4 \mathrm{DmiR}$. Further studies are required to clarify these issues.

Interestingly, miRNA-induced downregulation of PDE4D in the hippocampus did not alter $\alpha 2$ adrenergic receptor-mediated anesthesia, a surrogate measure of emesis in nonvomiting species (Robichaud et al., 2001, 2002a). In contrast, rolipram treatment or PDE4D deficiency decreased the duration of anesthesia; this is consistent with the contribution of PDE4 and, more specifically, PDE4D to emesis, the major side effect of PDE4 inhibitors (Dyke and Montana, 2002; Robichaud et al., 2001, 2002a,b).

In summary, using behavioral, neurochemical, immunohistochemical, and molecular biological approaches, we demonstrated for the first time the roles of PDE4D and its long-form isoforms in CAMP/CREB signaling-mediated memory and neurogenesis. Manipulations targeting long-form PDE4Ds in the hippocampus may alter CAMP/CREB signaling in a manner that affects memory and hippocampal neurogenesis but avoids emesis. These are supported by the findings that selective PDE4D allosteric modulators incompletely inhibit PDE4 activity and enhance memory but have reduced potential to cause emesis (Burgin et al., 2010). Our results may be beneficial for treatment of memory loss associated with neurodegenerative disorders such as Alzheimer's disease.

\section{References}

Abel T, Kandel E (1998) Positive and negative regulatory mechanisms that mediate long-term memory storage. Brain Res Brain Res Rev 26:360-378.

Baillie GS, MacKenzie SJ, McPhee I, Houslay MD (2000) Sub-family selective actions in the ability of Erk2 MAP kinase to phosphorylate and regulate the activity of PDE4 cyclic AMP-specific phosphodiesterases. Br J Pharmacol 131:811-819.

Barad M, Bourtchouladze R, Winder DG, Golan H, Kandel E (1998) Rolipram, a type IV-specific phosphodiesterase inhibitor, facilitates the establishment of long-lasting long-term potentiation and improves memory. Proc Natl Acad Sci U S A 95:15020-15025.

Barco A, Pittenger C, Kandel ER (2003) CREB, memory enhancement and the treatment of memory disorders: promises, pitfalls and prospects. Expert Opin Ther Targets 7:101-114.

Bolger GB, McPhee I, Houslay MD (1996) Alternative splicing of cAMPspecific phosphodiesterase mRNA transcripts: characterization of a novel tissue-specific isoform, RNPDE4A8. J Biol Chem 271:1065-1071.

Bolger GB, Erdogan S, Jones RE, Loughney K, Scotland G, Hoffmann R, Wilkinson I, Farrell C, Houslay MD (1997) Characterization of five different proteins produced by alternatively spliced mRNAs from the human cAMP-specific phosphodiesterase PDE4D gene. Biochem J 328:539-548. Bourtchouladze R, Lidge R, Catapano R, Stanley J, Gossweiler S, Romashko 
D, Scott R, Tully T (2003) A mouse model of Rubinstein-Taybi syndrome: defective long-term memory is ameliorated by inhibitors of phosphodiesterase 4. Proc Natl Acad Sci U S A 100:10518-10522.

Boyes BE, Kim SU, Lee V, Sung SC (1986) Immunohistochemical colocalization of S-100 $\beta$ and the glial fibrillary acidic protein in rat brain. Neuroscience 17:857-865.

Bruel-Jungerman E, Laroche S, Rampon C (2005) New neurons in the dentate gyrus are involved in the expression of enhanced long-term memory following environmental enrichment. Eur J Neurosci 21:513-521.

Burgin AB, Magnusson OT, Singh J, Witte P, Staker BL, Bjornsson JM, Thorsteinsdottir M, Hrafnsdottir S, Hagen T, Kiselyov AS, Stewart LJ, Gurney ME (2010) Design of phosphodiesterase 4D (PDE4D) allosteric modulators for enhancing cognition with improved safety. Nat Biotechnol 28:63-70.

Chandrasekaran A, Toh KY, Low SH, Tay SK, Brenner S, Goh DL (2008) Identification and characterization of novel mouse PDE4D isoforms: molecular cloning, subcellular distribution and detection of isoform-specific intracellular localization signals. Cell Signal 20:139-153.

Cherry JA, Davis RL (1999) Cyclic AMP phosphodiesterases are localized in regions of the mouse brain associated with reinforcement, movement, and affect. J Comp Neurol 407:287-301.

Cheung YF, Kan Z, Garrett-Engele P, Gall I, Murdoch H, Baillie GS, Camargo LM, Johnson JM, Houslay MD, Castle JC (2007) PDE4B5, a novel, super-short, brain-specific cAMP phosphodiesterase-4 variant whose isoform-specifying $\mathrm{N}$-terminal region is identical to that of cAMP phosphodiesterase-4D6 (PDE4D6). J Pharmacol Exp Ther 322:600-609.

Conti M, Richter W, Mehats C, Livera G, Park JY, Jin C (2003) Cyclic AMPspecific PDE4 phosphodiesterases as critical components of cyclic AMP signaling. J Biol Chem 278:5493-5496.

Cullen BR (2005) RNAi the natural way. Nat Genet 37:1163-1165.

de Lima MN, Laranja DC, Bromberg E, Roesler R, Schröder N (2005) Preor post-training administration of the NMDA receptor blocker MK-801 impairs object recognition memory in rats. Behav Brain Res 156:139-143.

Dlaboga D, Hajjhussein H, O'Donnell JM (2006) Regulation of phosphodiesterase-4 (PDE4) expression in mouse brain by repeated antidepressant treatment: comparison with rolipram. Brain Res 1096:104-112.

D'Sa C, Eisch AJ, Bolger GB, Duman RS (2005) Differential expression and regulation of the cAMP-selective phosphodiesterase type $4 \mathrm{~A}$ splice variants in rat brain by chronic antidepressant administration. Eur J Neurosci 22:1463-1475.

Dull T, Zufferey R, Kelly M, Mandel RJ, Nguyen M, Trono D, Naldini L (1998) A third-generation lentivirus vector with a conditional packaging system. J Virol 72:8463-8471.

Duman RS, Malberg J, Nakagawa S (2001) Regulation of adult neurogenesis by psychotropic drugs and stress. J Pharmacol Exp Ther 299:401-407.

Dyke HJ, Montana JG (2002) Update on the therapeutic potential of PDE4 inhibitors. Expert Opin Investig Drugs 11:1-13.

Egawa T, Mishima K, Matsumoto Y, Iwasaki K, Iwasaki K, Fujiwara M (1997) Rolipram and its optical isomers, phosphodiesterase 4 inhibitors, attenuated the scopolamine-induced impairments of learning and memory in rats. Jpn J Pharmacol 75:275-281.

Encinas JM, Vaahtokari A, Enikolopov G (2006) Fluoxetine targets early progenitor cells in the adult brain. Proc Natl Acad Sci USA 103:8233-8238.

Episkopou V (2005) SOX2 functions in adult neural stem cells. Trends Neurosci 28:219-221.

Epp JR, Spritzer MD, Galea LA (2007) Hippocampus-dependent learning promotes survival of new neurons in the dentate gyrus at a specific time during cell maturation. Neuroscience 149:273-285.

Fujioka T, Fujioka A, Duman RS (2004) Activation of cAMP signaling facilitates the morphological maturation of newborn neurons in adult hippocampus. J Neurosci 24:319-328.

Giorgi M, Modica A, Pompili A, Pacitti C, Gasbarri A (2004) The induction of cyclic nucleotide phosphodiesterase 4 gene (PDE4D) impairs memory in a water maze task. Behav Brain Res 154:99-106.

Gould E, Beylin A, Tanapat P, Reeves A, Shors TJ (1999) Learning enhances adult neurogenesis in the hippocampal formation. Nat Neurosci 2:260-265.

Graham V, Khudyakov J, Ellis P, Pevny L (2003) SOX2 functions to maintain neural progenitor identity. Neuron 39:749-765.

Grillo CA, Tamashiro KL, Piroli GG, Melhorn S, Gass JT, Newsom RJ, Reznikov LR, Smith A, Wilson SP, Sakai RR, Reagan LP (2007) Lentivirus- mediated downregulation of hypothalamic insulin receptor expression. Physiol Behav 92:691-701.

Hansen G, Jin S, Umetsu DT, Conti M (2000) Absence of muscarinic cholinergic airway responses in mice deficient in the cyclic nucleotide phosphodiesterase PDE4D. Proc Natl Acad Sci U S A 97:6751-6756.

Houslay MD (2001) PDE4 cAMP-specific phosphodiesterases. Prog Nucleic Acid Res Mol Biol 69:249-315.

Houslay MD (2010) Underpinning compartmentalised cAMP signalling through targeted cAMP breakdown. Trends Biochem Sci 35:91-100.

Houslay MD, Baillie GS, Maurice DH (2007) cAMP-Specific phosphodiesterase- 4 enzymes in the cardiovascular system: a molecular toolbox for generating compartmentalized cAMP signaling. Circ Res 100:950966.

Huston E, Lumb S, Russell A, Catterall C, Ross AH, Steele MR, Bolger GB, Perry MJ, Owens RJ, Houslay MD (1997) Molecular cloning and transient expression in COS7 cells of a novel human PDE4B cAMP-specific phosphodiesterase, HSPDE4B3. Biochem J 328:549-558.

Imanishi T, Sawa A, Ichimaru Y, Miyashiro M, Kato S, Yamamoto T, Ueki S (1997) Ameliorating effects of rolipram on experimentally induced impairments of learning and memory in rodents. Eur J Pharmacol 321:273-278.

Jin SL, Richard FJ, Kuo WP, D'Ercole AJ, Conti M (1999) Impaired growth and fertility of cAMP-specific phosphodiesterase PDE4D-deficient mice. Proc Natl Acad Sci U S A 96:11998-12003.

Johnston LA, Erdogan S, Cheung YF, Sullivan M, Barber R, Lynch MJ, Baillie GS, Van Heeke G, Adams DR, Huston E, Houslay MD (2004) Expression, intracellular distribution and basis for lack of catalytic activity of the PDE4A7 isoform encoded by the human PDE4A cAMP-specific phosphodiesterase gene. Biochem J 380:371-384.

Kempermann G, Gast D, Kronenberg G, Yamaguchi M, Gage FH (2003) Early determination and long-term persistence of adult-generated new neurons in the hippocampus of mice. Development 130:391-399.

Kolosionek E, Savai R, Ghofrani HA, Weissmann N, Guenther A, Grimminger F, Seeger W, Banat GA, Schermuly RT, Pullamsetti SS (2009) Expression and activity of phosphodiesterase isoforms during epithelial mesenchymal transition: the role of phosphodiesterase 4. Mol Biol Cell 20:4751-4765.

Li X, Huston E, Lynch MJ, Houslay MD, Baillie GS (2006) Phosphodiesterase-4 influences the PKA phosphorylation status and membrane translocation of G-protein receptor kinase 2 (GRK2) in HEK-293beta2 cells and cardiac myocytes. Biochem J 394:427-435.

Li YF, Huang Y, Amsdell SL, Xiao L, O’Donnell JM, Zhang HT (2009) Antidepressant- and anxiolytic-like effects of the phosphodiesterase-4 (PDE4) inhibitor rolipram on behavior depend on cyclic AMP-response element binding protein (CREB)-mediated neurogenesis in the hippocampus. Neuropsychopharmacology 34:2404-2419.

Lynch MJ, Baillie GS, Mohamed A, Li X, Maisonneuve C, Klussmann E, van Heeke G, Houslay MD (2005) RNA silencing identifies PDE4D5 as the functionally relevant cAMP phosphodiesterase interacting with beta arrestin to control the protein kinase A/AKAP79-mediated switching of the beta2-adrenergic receptor to activation of ERK in HEK293B2 cells. J Biol Chem 280:33178-33189.

Lynex CN, Li Z, Chen ML, Toh KY, Low RW, Goh DL, Tay SK (2008) Identification and molecular characterization of a novel PDE4D11 cAMP-specific phosphodiesterase isoform. Cell Signal 20:2247-2255.

MacKenzie SJ, Houslay MD (2000) Action of rolipram on specific PDE4 cAMP phosphodiesterase isoforms and on the phosphorylation of cAMPresponse-element-binding protein (CREB) and p38 mitogen-activated protein (MAP) kinase in U937 monocytic cells. Biochem J 347:571-578.

Malberg JE, Eisch AJ, Nestler EJ, Duman RS (2000) Chronic antidepressant treatment increases neurogenesis in adult hippocampus. J Neurosci 20:9104-9110.

Maurice T, Privat A (1997) SA4503, a novel cognitive enhancer with $\sigma 1$ receptor agonist properties, facilitates NMDA receptor-dependent learning in mice. Eur J Pharmacol 328:9-18.

McPhee I, Cochran S, Houslay MD (2001) The novel long PDE4A10 cyclic AMP phosphodiesterase shows a pattern of expression within brain that is distinct from the long PDE4A5 and short PDE4A1 isoforms. Cell Signal 13:911-918.

Millar JK, Pickard BS, Mackie S, James R, Christie S, Buchanan SR, Malloy MP, Chubb JE, Huston E, Baillie GS, Thomson PA, Hill EV, Brandon NJ, Rain JC, Camargo LM, Whiting PJ, Houslay MD, Blackwood DH, Muir 
WJ, Porteous DJ (2005) DISC1 and PDE4B are interacting genetic factors in schizophrenia that regulate cAMP signaling. Science 310:11871191.

Miró X, Pérez-Torres S, Puigdomènech P, Palacios JM, Mengod G (2002) Differential distribution of PDE4D splice variant mRNAs in rat brain suggests association with specific pathways and presynaptical localization. Synapse 45:259-269.

Monti B, Berteotti C, Contestabile A (2006) Subchronic rolipram delivery activates hippocampal CREB and Arc, enhances retention and slows down extinction of conditioned fear. Neuropsychopharmacology 31:278-286.

Morris RG, Garrud P, Rawlins JN, O’Keefe J (1982) Place navigation impaired in rats with hippocampal lesions. Nature 297:681-683.

Mullen R, Buck CR, Smith AM (1992) NeuN, a neuronal specific nuclear protein in vertebrates. Development 116:201-211.

Nakagawa S, Kim JE, Lee R, Malberg JE, Chen J, Steffen C, Zhang YJ, Nestler EJ, Duman RS (2002a) Regulation of neurogenesis in adult mouse hippocampus by cAMP and the cAMP response element-binding protein. J Neurosci 22:3673-3682.

Nakagawa S, Kim JE, Lee R, Chen J, Fujioka T, Malberg J, Tsuji S, Duman RS (2002b) Localization of phosphorylated cAMP response element binding protein in immature neurons of adult hippocampus. J Neurosci 22:9868-9876.

Némoz G, Zhang R, Sette C, Conti M (1996) Identification of cyclic AMPphosphodiesterase variants from the PDE4D gene expressed in human peripheral mononuclear cells. FEBS Lett 384:97-102.

O'Donnell JM, Zhang HT (2004) Antidepressant effects of inhibitors of cAMP phosphodiesterase (PDE4). Trends Pharmacol Sci 25:158-163.

Otmakhov N, Khibnik L, Otmakhova N, Carpenter S, Riahi S, Asrican B, Lisman J (2004) Forskolin-induced LTP in the CA1 hippocampal region is NMDA receptor dependent. J Neurophysiol 91:1955-1962.

Paxinos G, Franklin KBJ (2001) The mouse brain in stereotaxic coordinates. Ed 2. San Diego: Academic.

Pérez-Torres S, Miró X, Palacios JM, Cortés R, Puigdoménech P, Mengod G (2000) Phosphodiesterase type 4 isozymes expression in human brain examined by in situ hybridization histochemistry and $\left[{ }^{3} \mathrm{H}\right]$ rolipram binding autoradiography: comparison with monkey and rat brain. J Chem Neuroanat 20:349-374.

Remondes M, Schuman EM (2004) Role for a cortical input to hippocampal area CA1 in the consolidation of a long-term memory. Nature 431: 699-703.

Richter W, Jin SL, Conti M (2005) Splice variants of the cyclic nucleotide phosphodiesterase PDE4D are differentially expressed and regulated in rat tissue. Biochem J 388:803-811.

Robichaud A, Savoie C, Stamatiou PB, Tattersall FD, Chan CC (2001) PDE4 inhibitors induce emesis in ferrets via a noradrenergic pathway. Neuropharmacology 40:262-269.

Robichaud A, Savoie C, Stamatiou PB, Lachance N, Jolicoeur P, Rasori R, Chan CC (2002a) Assessing the emetic potential of PDE4 inhibitors in rats. Br J Pharmacol 135:113-118.

Robichaud A, Stamatiou PB, Jin SL, Lachance N, MacDonald D, Laliberté F, Liu S, Huang Z, Conti M, Chan CC (2002b) Deletion of phosphodiesterase $4 \mathrm{D}$ in mice shortens alpha(2)-adrenoceptor-mediated anesthesia, a behavioral correlate of emesis. J Clin Invest 110:1045-1052.

Romano A, Delorenzi A, Pedreira ME, Tomsic D, Maldonado H (1996) Acute administration of a permeant analog of cAMP and a phosphodiesterase inhibitor improve long-term habituation in the crab Chasmagnathus. Behav Brain Res 75:119-125.

Rutten K, Misner DL, Works M, Blokland A, Novak TJ, Santarelli L, Wallace TL (2008) Enhanced long-term potentiation and impaired learning in phosphodiesterase 4D-knockout (PDE4D) mice. Eur J Neurosci 28:625-632.

Sasaki T, Kitagawa K, Omura-Matsuoka E, Todo K, Terasaki Y, Sugiura S, Hatazawa J, Yagita Y, Hori M (2007) The phosphodiesterase inhibitor rolipram promotes survival of newborn hippocampal neurons after ischemia. Stroke 38:1597-1605.

Schmidt HD, Duman RS (2007) The role of neurotrophic factors in adult hippocampal neurogenesis, antidepressant treatments and animal models of depressive-like behavior. Behav Pharmacol 18:391-418.

Schneider HH (1984) Brain cAMP response to phosphodiesterase inhibitors in rats killed by microwave irradiation or decapitation. Biochem Pharmacol 33:1690-1693.

Schratt GM, Tuebing F, Nigh EA, Kane CG, Sabatini ME, Kiebler M, Greenberg ME (2006) A brain-specific microRNA regulates dendritic spine development. Nature 439:283-289.

Shors TJ, Miesegaes G, Beylin A, Zhao M, Rydel T, Gould E (2001) Neurogenesis in the adult is involved in the formation of trace memories. Nature 410:372-376.

Siuciak JA, McCarthy SA, Chapin DS, Martin AN (2008) Behavioral and neurochemical characterization of mice deficient in the phosphodiesterase-4B (PDE4B) enzyme. Psychopharmacology 197:115-126.

Stegmeier F, Hu G, Rickles RJ, Hannon GJ, Elledge SJ (2005) A lentiviral microRNA-based system for single-copy polymerase II-regulated RNA interference in mammalian cells. Proc Natl Acad Sci US A 102: 13212-13217.

van Praag H, Schinder AF, Christie BR, Toni N, Palmer TD, Gage FH (2002) Functional neurogenesis in the adult hippocampus. Nature 415:10301034.

Villiger JW, Dunn AJ (1981) Phosphodiesterase inhibitors facilitate memory for passive avoidance conditioning. Behav Neural Biol 31:354-359.

Zala D, Bensadoun JC, Pereira de Almeida L, Leavitt BR, Gutekunst CA, Aebischer P, Hayden MR, Déglon N (2004) Long-term lentiviralmediated expression of ciliary neurotrophic factor in the striatum of Huntington's disease transgenic mice. Exp Neurol 185:26-35.

Zentilin L, Giacca M (2004) In vivo transfer and expression of genes coding for short interfering RNAs. Curr Pharm Biotechnol 5:341-347.

Zeringue HC, Constantine-Paton M (2004) Post-transcriptional gene silencing in neurons. Curr Opin Neurobiol 14:654-659.

Zhang HT (2009) Cyclic AMP-specific phosphodiesterase-4 as a target for the development of antidepressant drugs. Curr Pharm Des 15:1688-1698.

Zhang HT, O'Donnell JM (2000) Effects of rolipram on scopolamineinduced impairment of working and reference memory in the radial-arm maze tests in rats. Psychopharmacology 150:311-316.

Zhang HT, Crissman AM, Dorairaj NR, Chandler LJ, O’Donnell JM (2000) Inhibition of cyclic AMP phosphodiesterase (PDE4) reverses memory deficits associated with NMDA receptor antagonism. Neuropsychopharmacology 23:198-204.

Zhang HT, Huang Y, Jin SL, Frith SA, Suvarna N, Conti M, O’Donnell JM (2002) Antidepressant-like Profile and Reduced Sensitivity to Rolipram in Mice Deficient in the PDE4D Phosphodiesterase Enzyme. Neuropsychopharmacology 27:587-595.

Zhang HT, Zhao Y, Huang Y, Dorairaj NR, Chandler LJ, O’Donnell JM (2004) Inhibition of the phosphodiesterase 4 (PDE4) enzyme reverses memory deficits produced by infusion of the MEK inhibitor U0126 into the CAl subregion of the rat hippocampus. Neuropsychopharmacology 29:1432-1439.

Zhang HT, Huang Y, Suvarna NU, Deng C, Crissman AM, Hopper AT, De Vivo M, Rose GM, O'Donnell JM (2005) Effects of the novel PDE4 inhibitors MEM1018 and MEM1091 on memory in the radial-arm maze and inhibitory avoidance tests in rats. Psychopharmacology 179:613-619.

Zhang HT, Huang Y, Masood A, Stolinski LR, Li Y, Zhang L, Dlaboga D, Jin SL, Conti M, O’Donnell JM (2008) Anxiogenic-like behavioral phenotype of mice deficient in phosphodiesterase 4B (PDE4B). Neuropsychopharmacology 33:1611-1623.

Zufferey R, Dull T, Mandel RJ, Bukovsky A, Quiroz D, Naldini L, Trono D (1998) Self-inactivating lentivirus vector for safe and efficient in vivo gene delivery. J Virol 72:9873-9880. 